\title{
Dynamic Surfaces-Degradable Polyester Networks That Resist Protein Adsorption
}

\author{
Gaoyan Mu, ${ }^{1}$ C. K. Pandiyarajan, ${ }^{2}$ Xiuyuan Lu, ${ }^{1}$ Matt Weaver, ${ }^{1}$ Jan Genzer, ${ }^{2}$
}

Christopher B. Gorman*1

${ }^{1}$ Department of Chemistry, North Carolina State University, Raleigh, NC 27695-7905, USA

${ }^{2}$ Department of Chemical \& Biomolecular Engineering, North Carolina State University,

Raleigh, NC 27695-7905, USA

\section{Table of Contents}

Table S1. Molecular weight-related information of polymers with various crosslinker content and corresponding gel fractions and thickness of network films ......................S3

Scheme S1. Synthesis of epoxymethoxytriethylene glycol (ETEG) .............................. 4

Scheme S2. Synthesis of epoxy-benzophenone (EBP) ………………………….......... S4

Scheme S3. Ring-opening polymerization of epoxy-benzophenone (EBP) and epoxymethoxytriethylene glycol (ETEG) ……………...............................................

Scheme S4. Synthesis of 4-[3-(Triethoxysilyl)propyloxy]- benzophenone (TESPBP)

Scheme S5. Synthesis of S-(3-(4-benzoylphenoxy)propyl) ethanethioate...................... S5

Scheme S6. Synthesis of (((disulfanediylbis(propane-3,1-diyl))-bis(oxy))-bis

(4,1-phenylene))bis(phenylmethanone) ………………............................................... 5

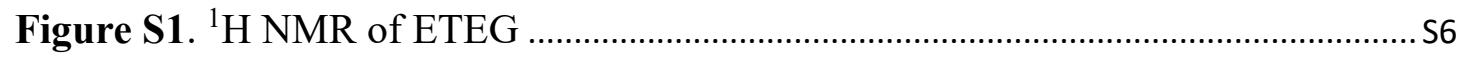

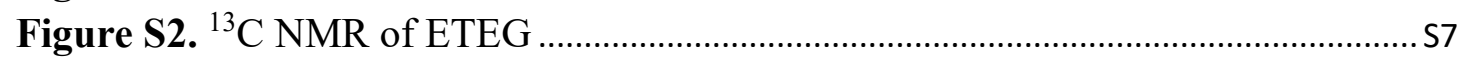

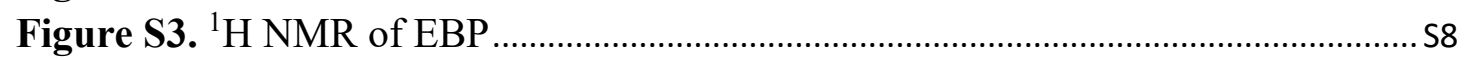

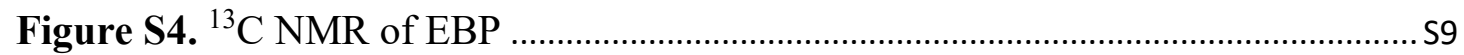

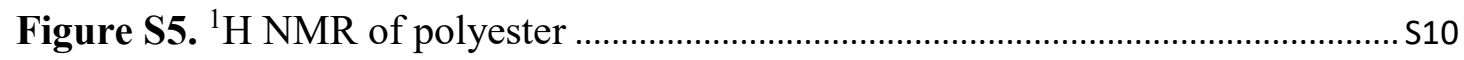

Figure S6. ${ }^{13} \mathrm{C}$ NMR of polyester .............................................................................. S11

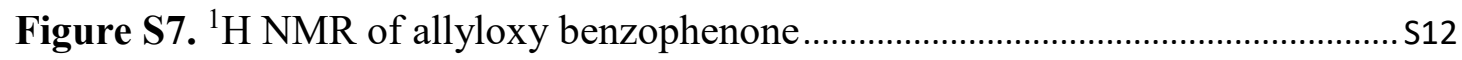

Figure S8. ${ }^{13} \mathrm{C}$ NMR of allyloxy benzophenone............................................................ $\mathrm{S} 13$

Figure S9. ${ }^{1} \mathrm{H}$ NMR of polyether ................................................................................ S14

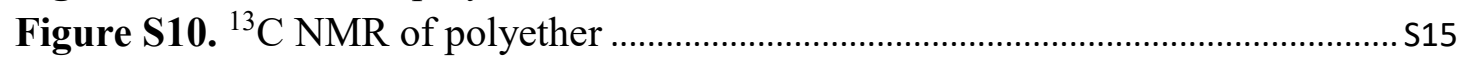

Mu et al., "Supporting Information for Dynamic Surfaces..." Page S1 of S32 
Figure S11. ${ }^{1} \mathrm{H}$ NMR of TESPBP.

Figure S12. ${ }^{1} \mathrm{H}$ NMR of TESPBP.

Figure S13. Gel Fraction versus irradiation time of samples with different percentage

of EBP incorporation S18

Figure S14. Percentage change in thickness versus $\mathrm{pH}$ for samples with various gel fractions $(\mathrm{GF}=0.60,0.72,0.86,0.93)$ S18

Figure S15. ${ }^{1} \mathrm{H}$ NMR of polyester before and after degradation in basic solution..... S19 Figure S16. ${ }^{13} \mathrm{C}$ NMR of polyester before and after degradation in basic solution ...S19 Figure S17. Degradation of polymers under acidic conditions shown as a percentage change in thickness versus immersion time S20

Figure S18. ATR-FTIR spectra of polyester network film spin-coated on a gold surface and incubated in $\mathrm{pH} 7.4$ buffer solution overnight S20

Figure S19. ${ }^{1} \mathrm{H}$ NMR of S-(3-(4-benzoylphenoxy)propyl) ethanethiolate.................... S21

Figure S20. ${ }^{13} \mathrm{C}$ NMR of S-(3-(4-benzoylphenoxy)propyl) ethanethiolate ................. S22

Figure S21. ${ }^{1} \mathrm{H}$ NMR of dibenzophenone disulfide ........................................................ 523

Figure S22. ${ }^{13} \mathrm{C}$ NMR of dibenzophenone disulfide....................................................... $\$ 24$

Figure S23. The degradation fitting curve of 0.57 gel fraction network ...................... S25

Figure S24. The degradation fitting curve of 0.60 gel fraction network ...................... 525

Figure S25. The degradation fitting curve of 0.72 gel fraction network .................... S26

Figure S26. The degradation fitting curve of 0.76 gel fraction network ..................... 226

Figure S27. The degradation fitting curve of 0.81 gel fraction network .....................S27

Figure S28. The degradation fitting curve of 0.86 gel fraction network ..................... S27

Figure S29. The degradation fitting curve of 0.88 gel fraction network .................... S28

Figure S30. The degradation fitting curve of 0.92 gel fraction network .................... S28

Figure S31. The degradation fitting curve of 0.93 gel fraction network ...................... S29

Figure S32. Fluorescence microscopy images showing BSA adsorption on thin films with various EBP ratio (a-f: $2.5 \%, 3.5 \%, 4.3 \%, 5 \%, 7.5 \%, 10 \%$ ) after $47.5 \mathrm{~h}$ immersion in FITC-BSA stock solution. The scale bars are $50 \mu \mathrm{m}$. ............................ 229

Figure S33. Roughness characterization of the polyester film by AFM .....................S30

Figure S34. Roughness characterization of the polyether film by AFM ...................... $\mathrm{S31}$

Figure S35. Roughness characterization of the polystyrene film by AFM .................. $\mathrm{S} 32$ 
Table S1. Molecular weight-related information of polymers with various crosslinker content and corresponding gel fractions and thickness of network films

\begin{tabular}{|c|c|c|c|c|c|c|}
\hline $\begin{array}{c}\text { EBP Ratio } \\
(\%)\end{array}$ & $\begin{array}{c}\mathrm{M}_{\mathrm{n}} \\
(\mathrm{kg} / \mathrm{mol})^{\mathrm{a}}\end{array}$ & $Đ$ & $\overline{D P}^{\mathrm{a}}$ & $X_{\text {avg }}$ & Gel fraction & $\begin{array}{c}\text { Dry thickness } \\
\text { (nm) }\end{array}$ \\
\hline 2.2 & 5.1 & 1.6 & 15 & 66 & $0.37 \pm 0.02$ & $28 \pm 1.1$ \\
\hline 2.4 & 4.2 & 1.8 & 13 & 62 & $0.57 \pm 0.03$ & $41 \pm 0.44$ \\
\hline 3.6 & 3.0 & 1.6 & 9 & 65 & $0.58 \pm 0.01$ & $42 \pm 0.75$ \\
\hline 3.4 & 6.8 & 1.9 & 20 & 136 & $0.60 \pm 0.01$ & $42 \pm 1.0$ \\
\hline 3.5 & 3.4 & 1.4 & 10 & 70 & $0.60 \pm 0.01$ & $36 \pm 0.49$ \\
\hline 3.7 & 4.1 & 1.6 & 13 & 96 & $0.68 \pm 0.02$ & $44 \pm 0.43$ \\
\hline 4.3 & 4.3 & 1.5 & 13 & 112 & $0.74 \pm 0.01$ & $44 \pm 0.83$ \\
\hline 3.7 & 5.0 & 1.6 & 15 & 111 & $0.76 \pm 0.03$ & $41 \pm 0.72$ \\
\hline 5.0 & 6.6 & 1.8 & 19 & 190 & $0.81 \pm 0.01$ & $44 \pm 0.83$ \\
\hline 5.0 & 4.1 & 1.8 & 12 & 120 & $0.85 \pm 0.01$ & $64 \pm 0.79$ \\
\hline 5.8 & 4.6 & 1.7 & 13 & 151 & $0.86 \pm 0.01$ & $66 \pm 1.2$ \\
\hline 6.1 & 3.7 & 1.8 & 11 & 134 & $0.88 \pm 0.01$ & $67 \pm 1.7$ \\
\hline 6.7 & 3.5 & 1.5 & 10 & 134 & $0.90 \pm 0.02$ & $70 \pm 0.30$ \\
\hline 6.9 & 4.6 & 1.7 & 14 & 193 & $0.92 \pm 0.01$ & $73 \pm 2.4$ \\
\hline 6.7 & 3.7 & 1.7 & 11 & 147 & $0.93 \pm 0.01$ & $63 \pm 2.4$ \\
\hline 10 & 3.9 & 1.4 & 12 & 240 & $0.94 \pm 0.02$ & $60 \pm 0.92$ \\
\hline
\end{tabular}

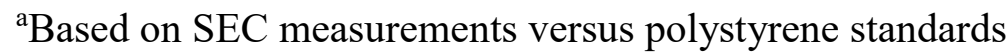


Scheme S1. Synthesis of epoxymethoxytriethylene glycol (ETEG)

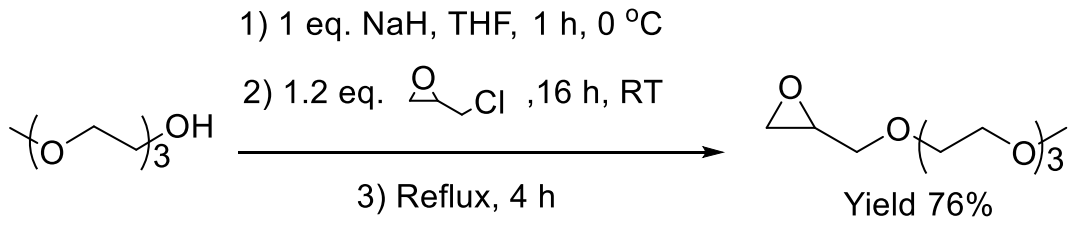

Scheme S2. Synthesis of epoxy-benzophenone (EBP)

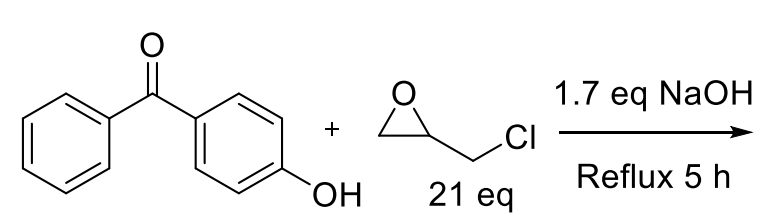<smiles>O=C(c1ccccc1)c1ccc(OCC2CO2)cc1</smiles>

Yield 65\%

Scheme S3. Ring-opening polymerization of epoxy-benzophenone (EBP) and epoxymethoxytriethylene glycol (ETEG)<smiles>COCC[Ge](C)(C)CC1CO1</smiles>

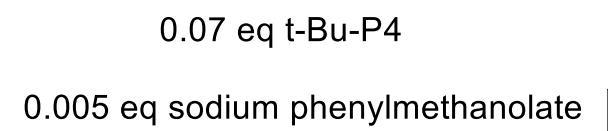<smiles>COCCOCC(COCc1ccccc1)OCC(C)O</smiles>
$80 \mathrm{uL}$ toluene, RT, 3days<smiles>COc1ccc(C(=O)c2ccccc2)cc1</smiles>

Yield 82\% 
Scheme S4. Synthesis of 4-[3-(Triethoxysilyl)propyloxy]- benzophenone (TESPBP)<smiles></smiles>

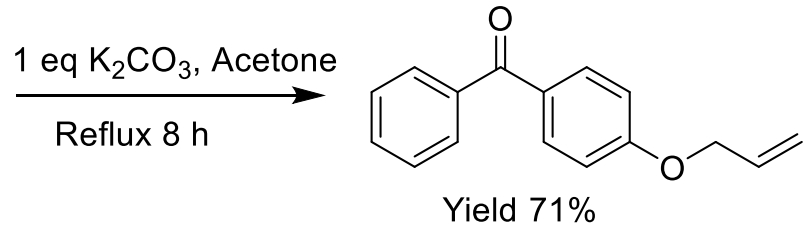

5.2 eq Triethoxysilane, 1.5 eq Pt/C Reflux $5 \mathrm{~h}$<smiles>CCO[Si](CCCOc1ccc(C(=O)c2ccccc2)cc1)(OCC)OCC</smiles>

Scheme S5. Synthesis of S-(3-(4-benzoylphenoxy)propyl) ethanethioate<smiles>C=CCOc1ccc(C(=O)c2ccccc2)cc1</smiles>

Scheme S6. Synthesis of (((disulfanediylbis(propane-3,1-diyl))-bis(oxy))-bis (4,1-phenylene))bis(phenylmethanone)<smiles>CC(=O)SCCCOc1ccc(C(=O)c2ccccc2)cc1</smiles><smiles>COCCOCCO</smiles><smiles>O=C(c1ccccc1)c1ccc(OCCCSSCCCOc2ccc(C(=O)c3ccccc3)cc2)cc1</smiles> 


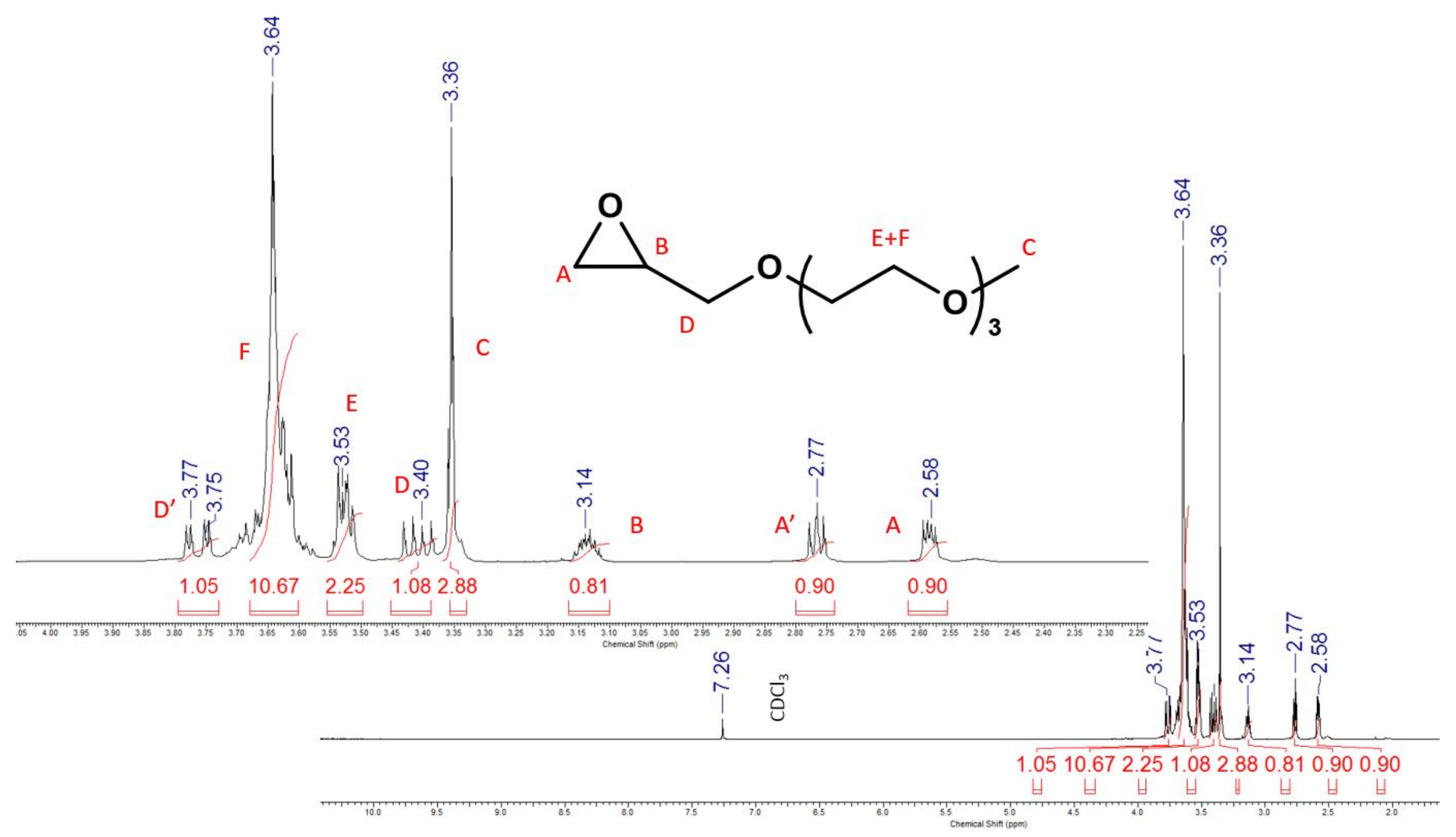

Figure S1. ${ }^{1} \mathrm{H}$ NMR of ETEG 


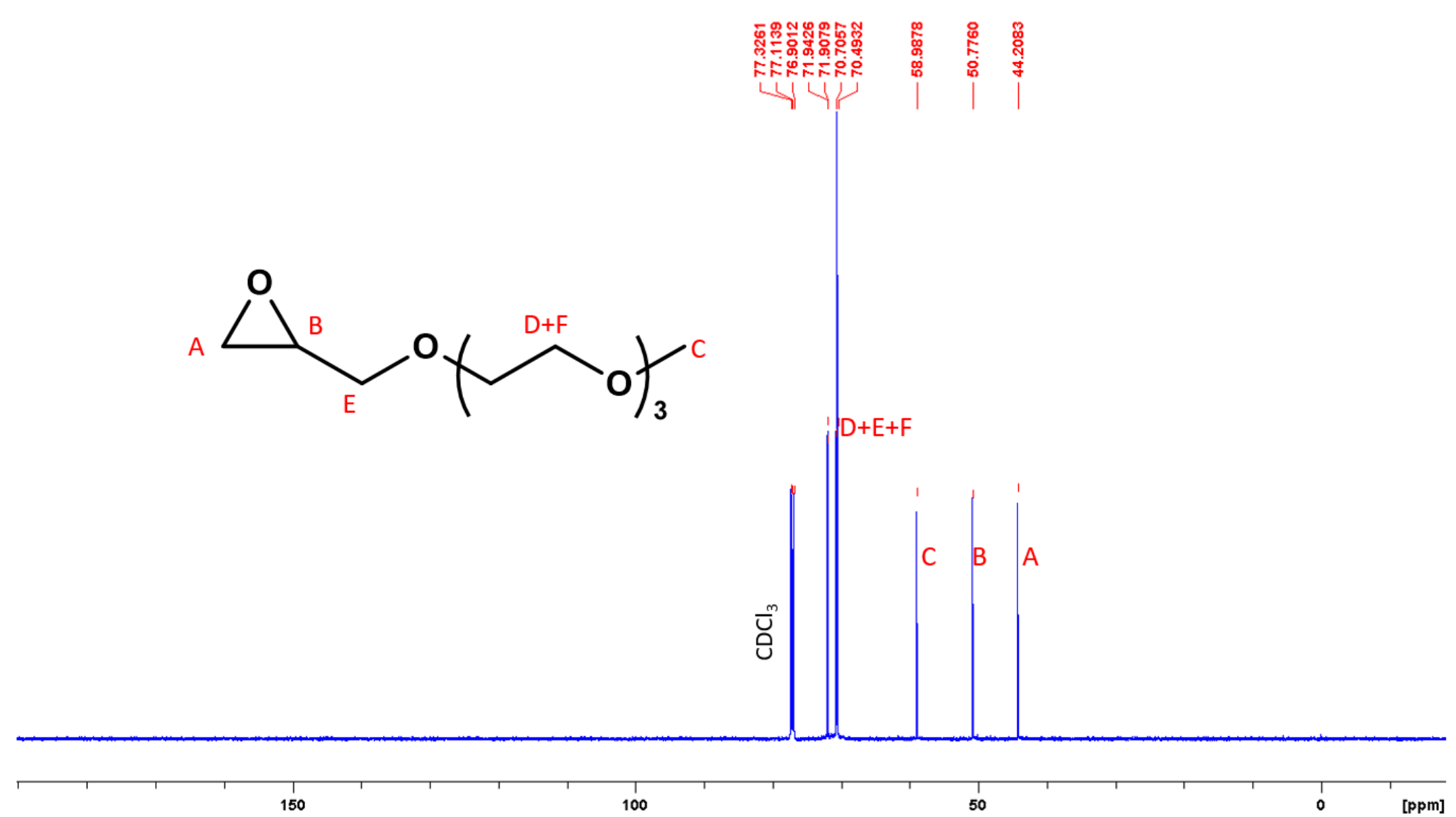

Figure S2. ${ }^{13} \mathrm{C}$ NMR of ETEG 


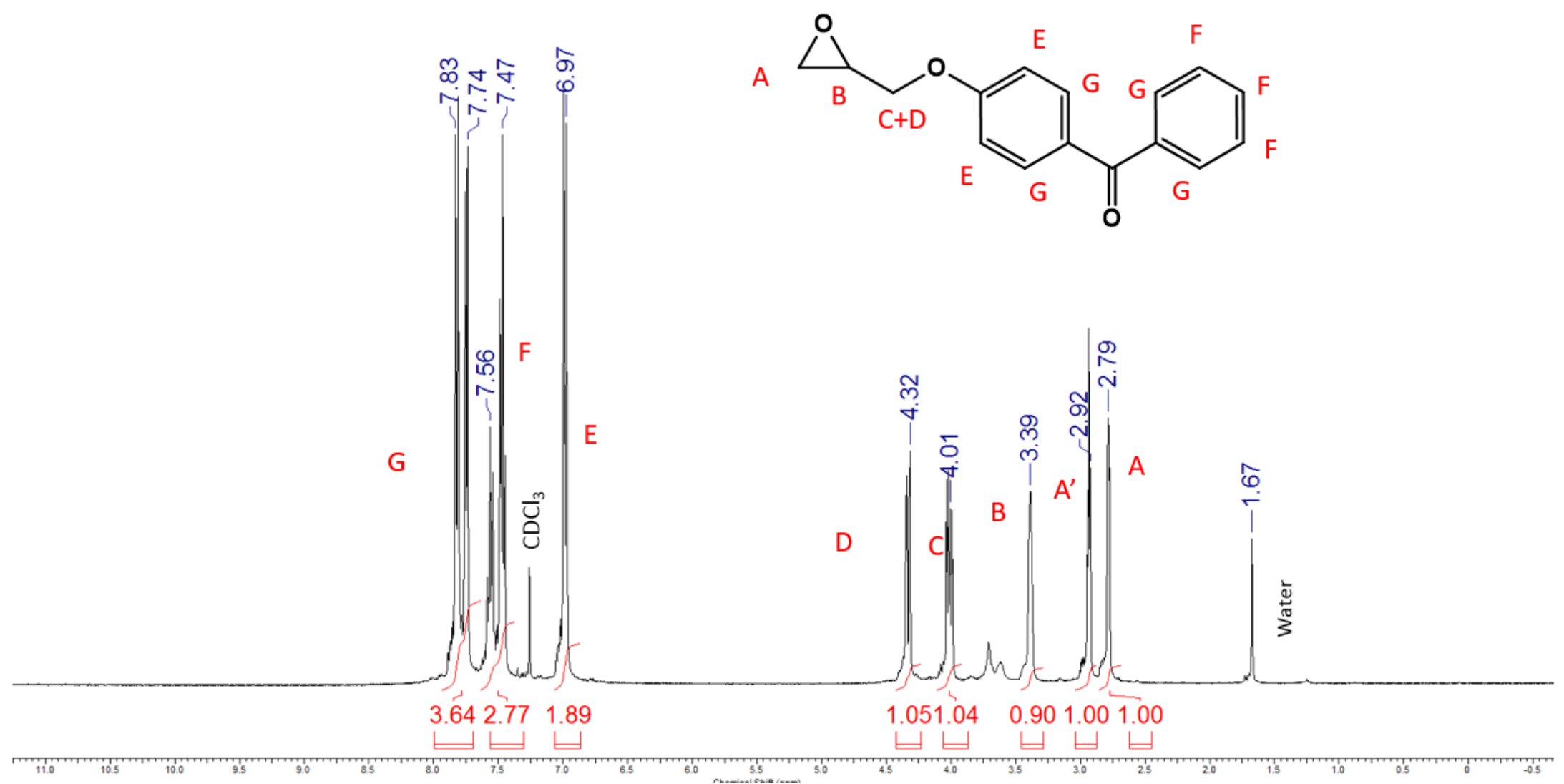

Figure S3. ${ }^{1} \mathrm{H}$ NMR of EBP 


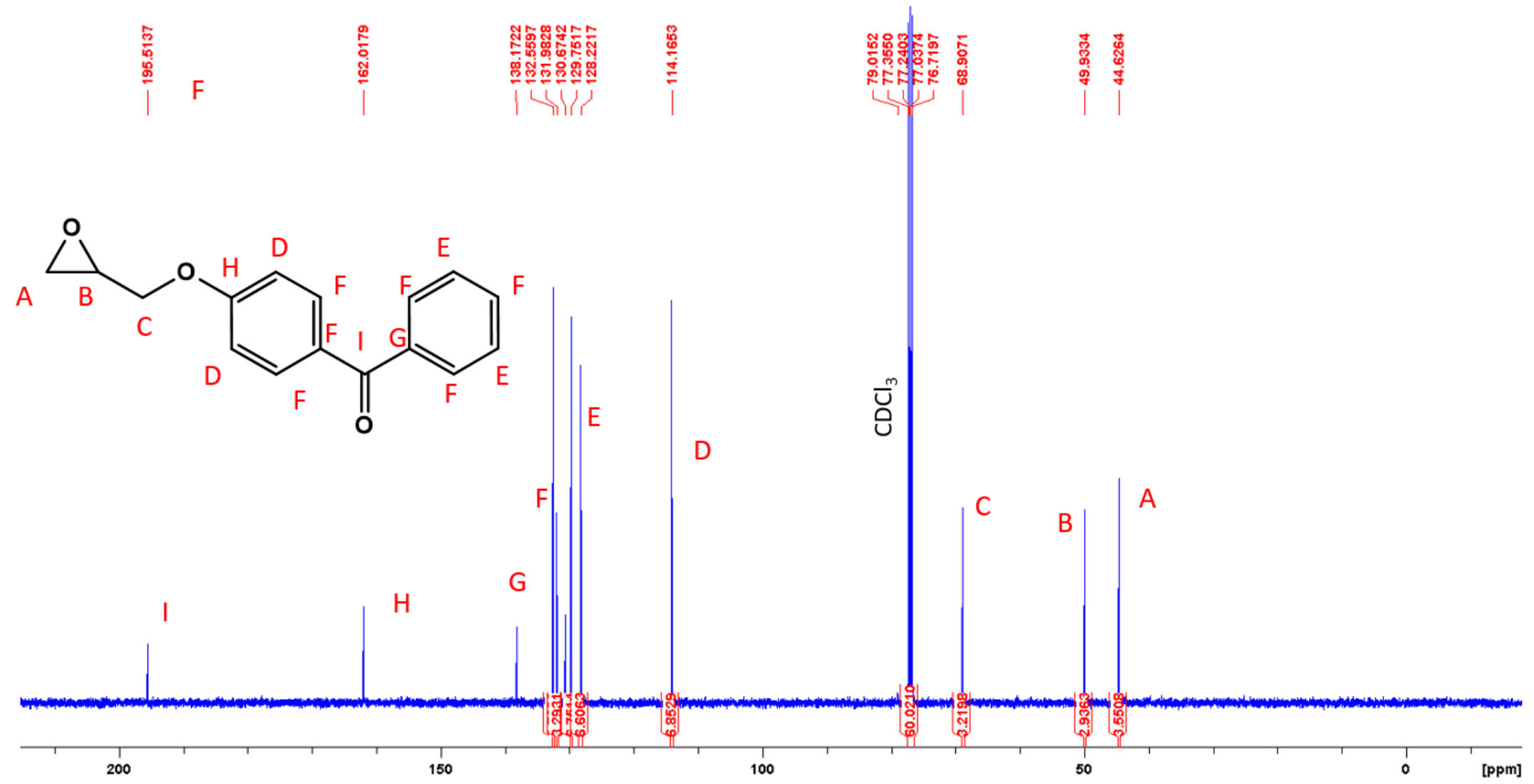

Figure $\mathbf{S 4} .{ }^{13} \mathrm{C}$ NMR of EBP 


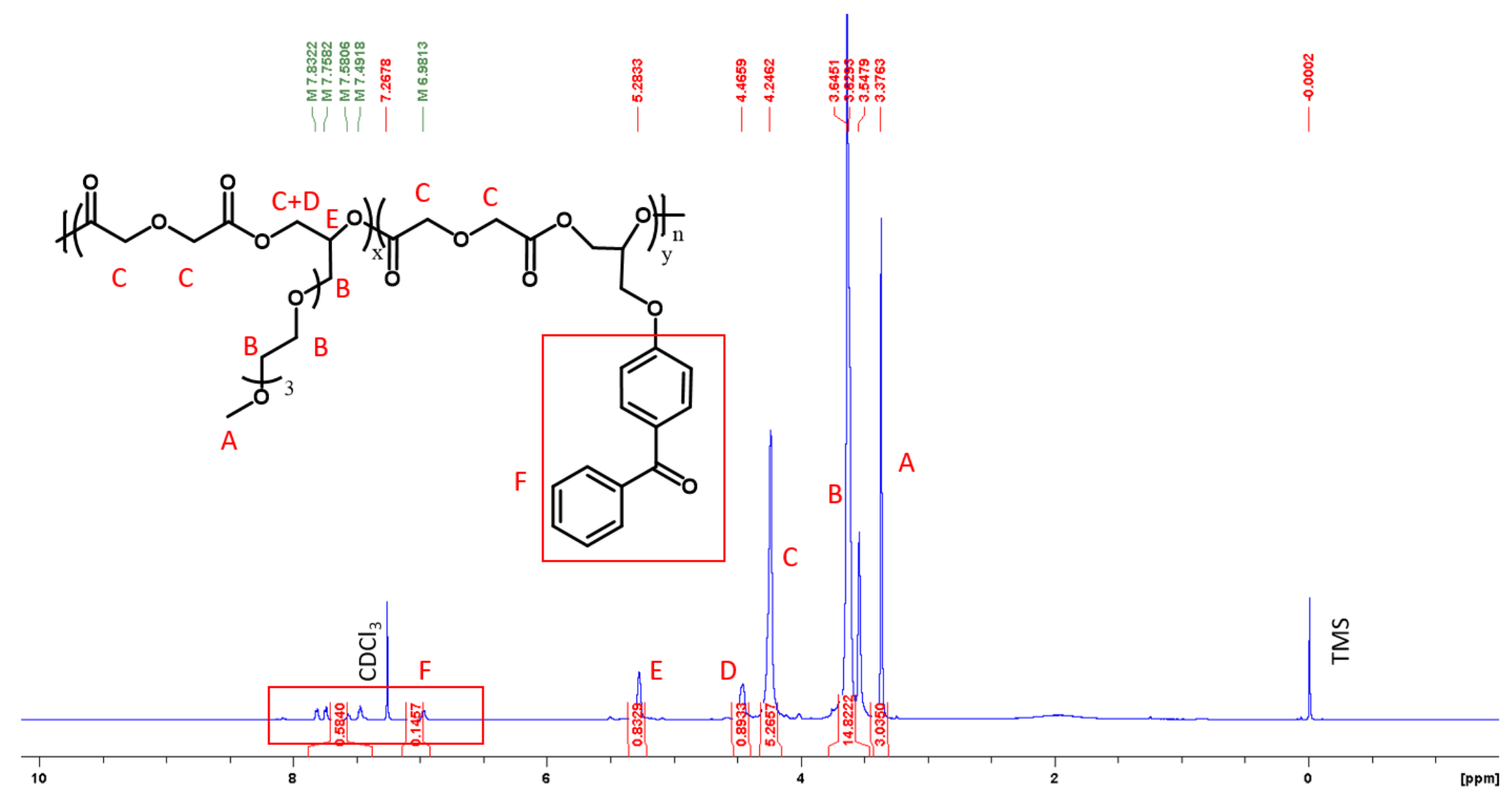

Figure S5. ${ }^{1} \mathrm{H}$ NMR of polyester (sample 2) . A refers to methoxy end group of ETEG. F refers to benzophenone. C refers to DGA. Integration of $\mathrm{C} / 5: \mathrm{A} / 3: \mathrm{F} / 9$ gives the mole ratio of DGA:ETEG:EBP 


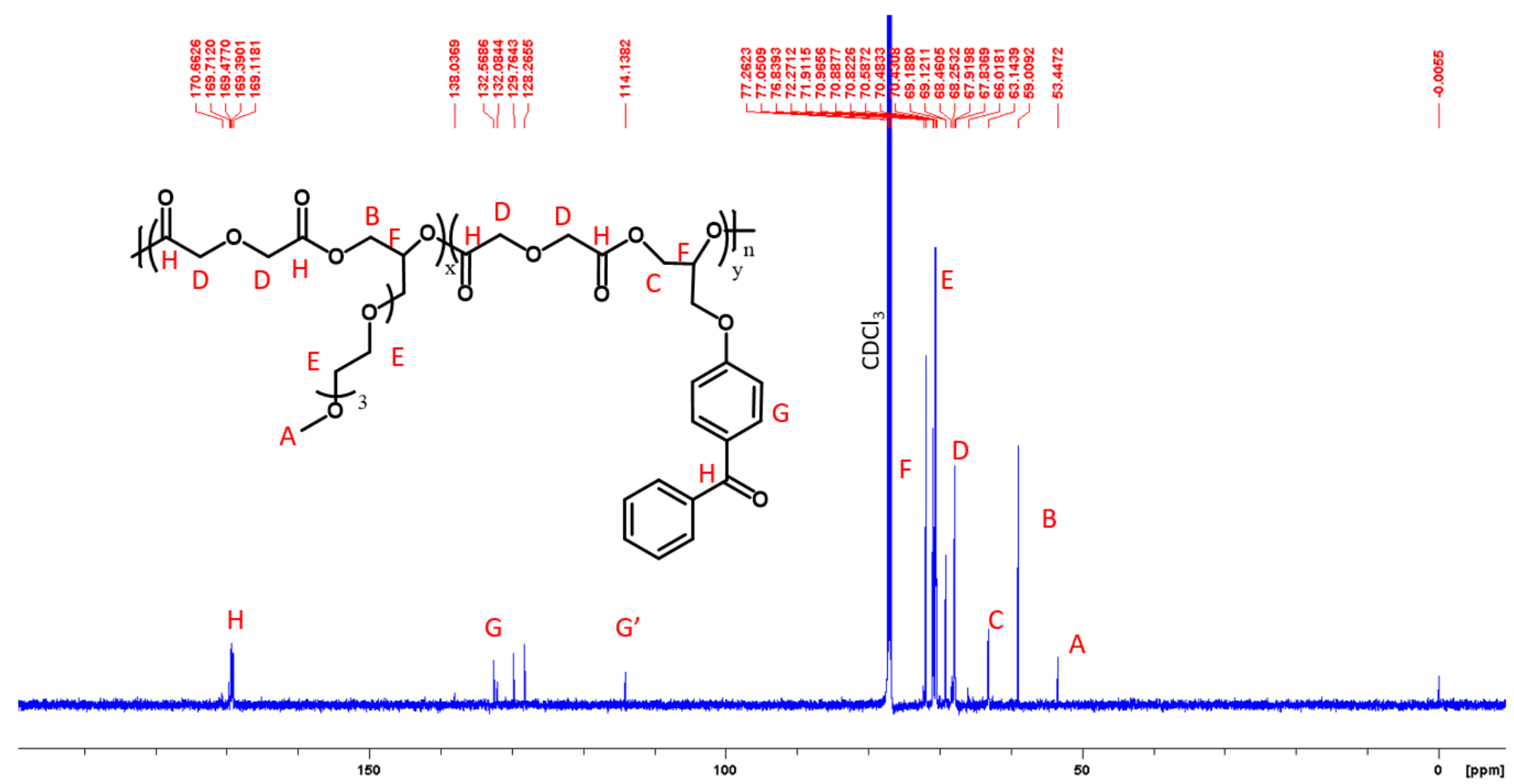

Figure S6. ${ }^{13} \mathrm{C}$ NMR of polyester 


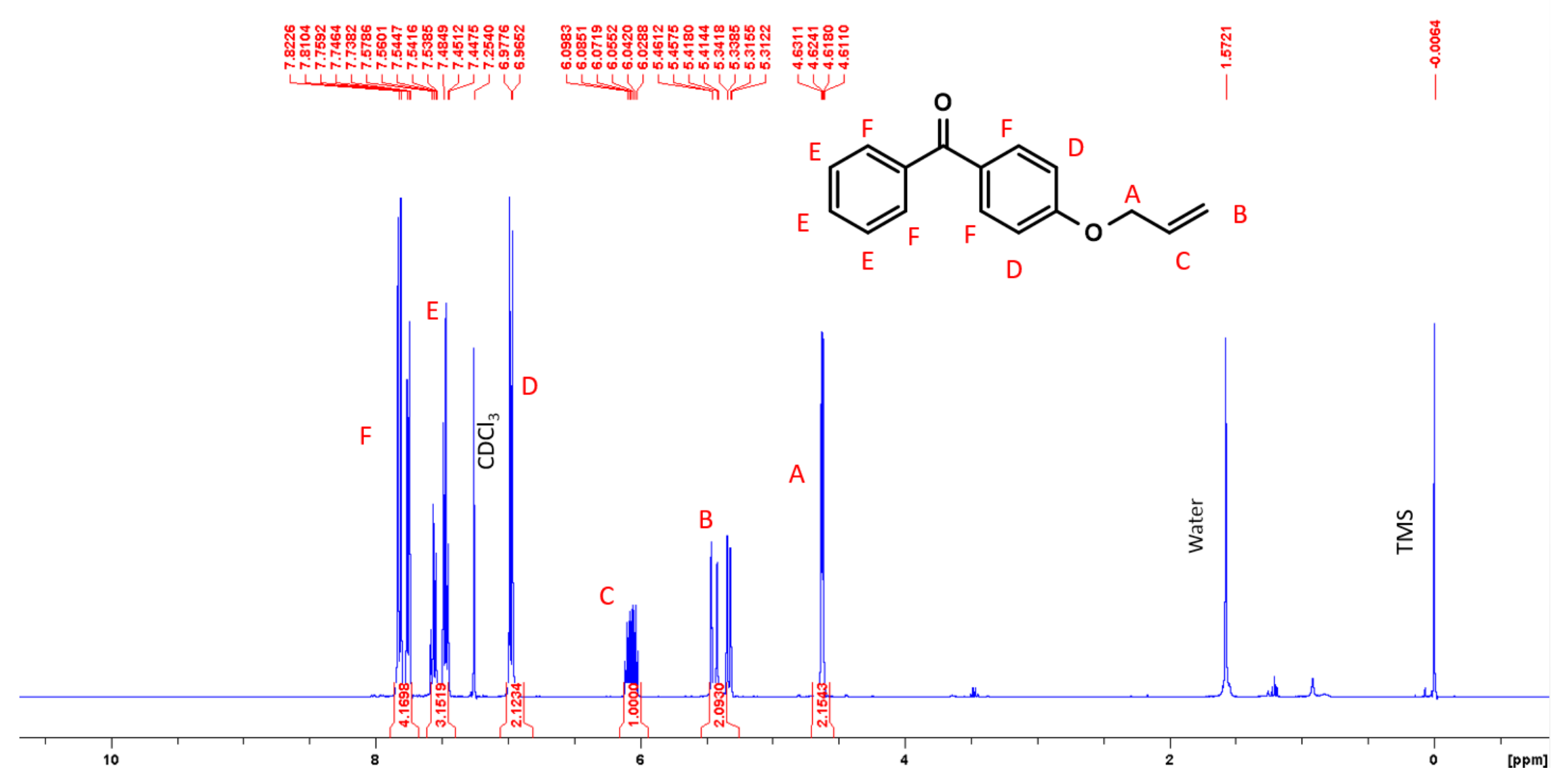

Figure S7. ${ }^{1} \mathrm{H}$ NMR of allyloxy benzophenone 


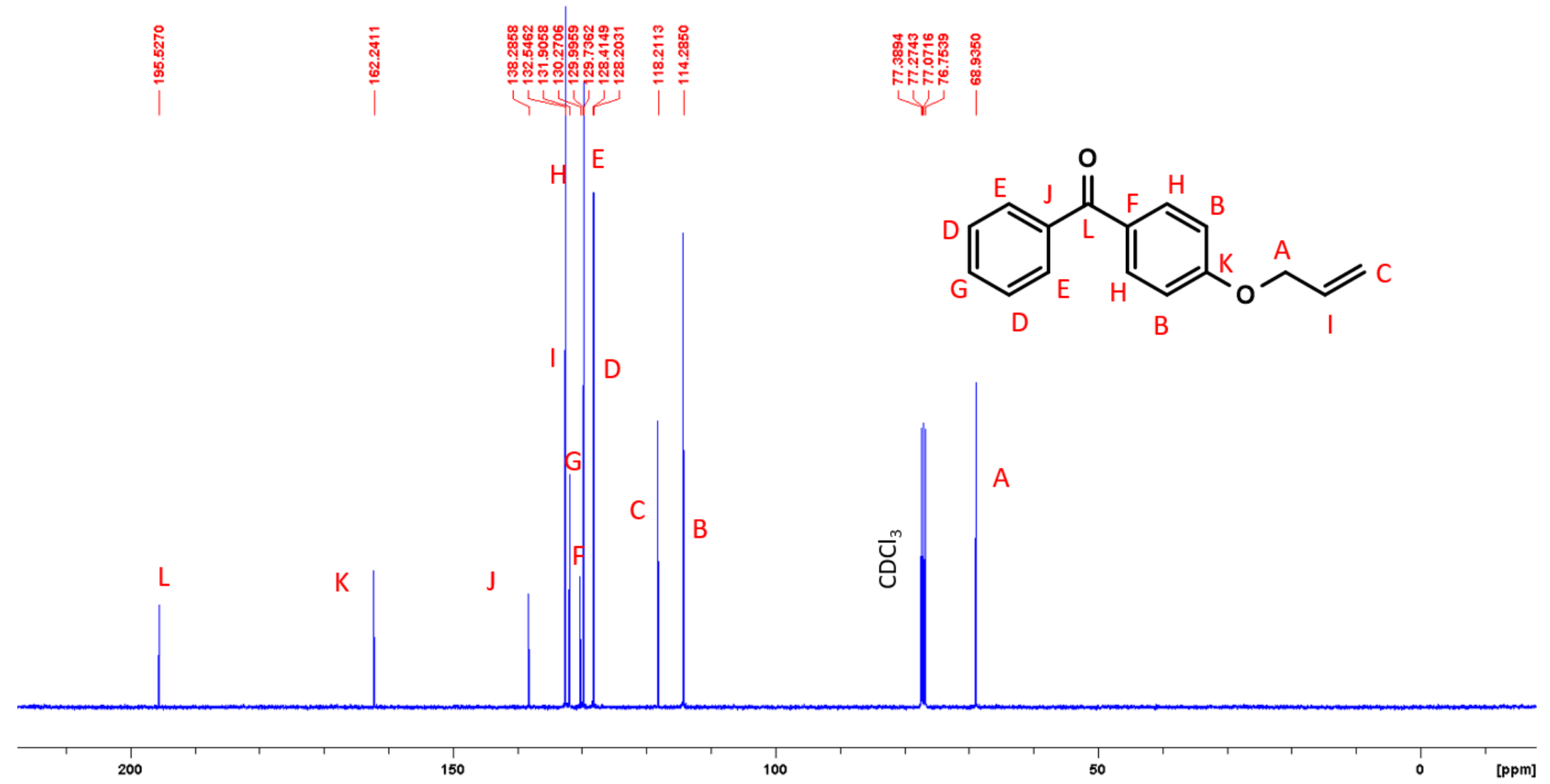

Figure S8. ${ }^{13} \mathrm{C}$ NMR of allyloxy benzophenone 


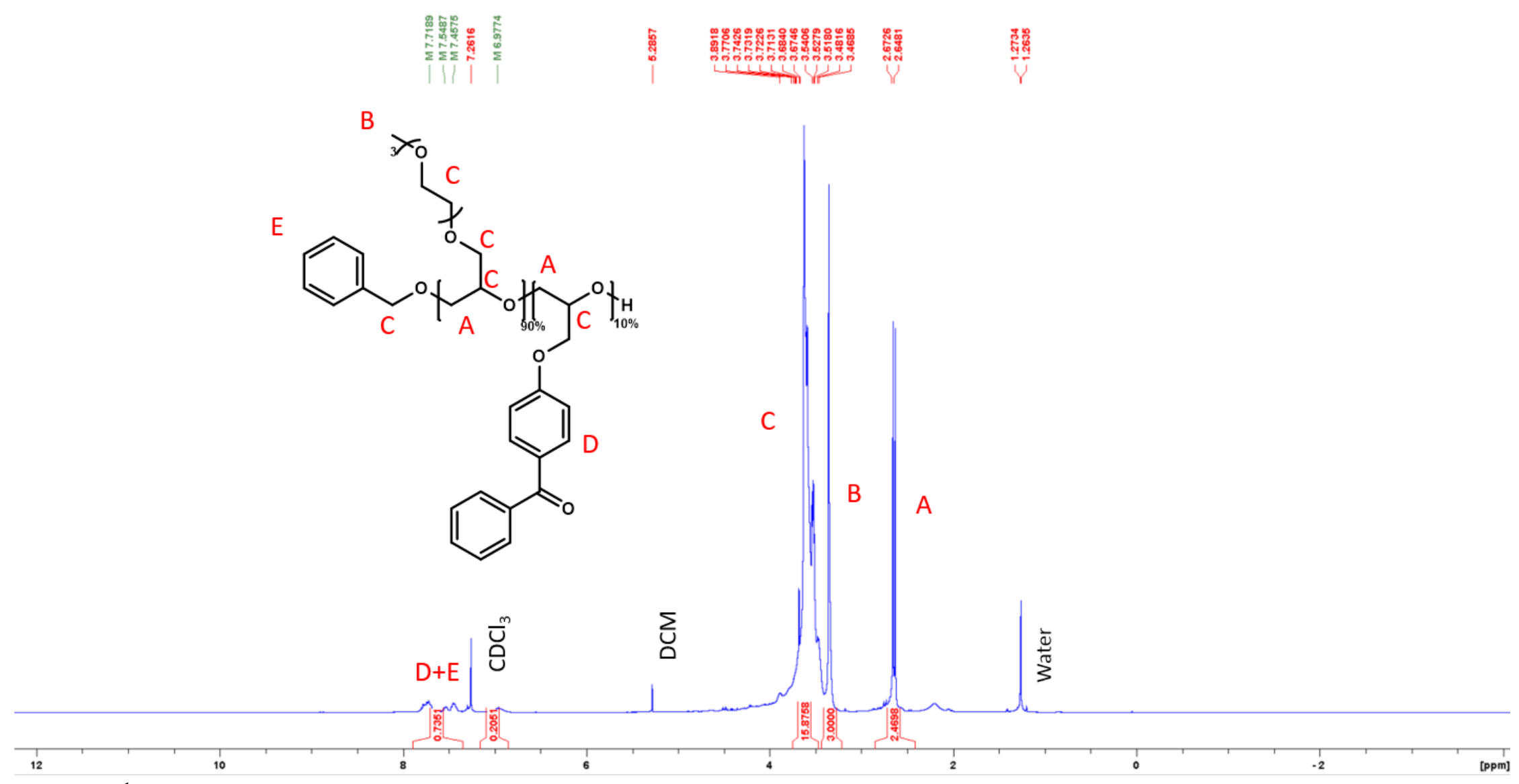

Figure S9. ${ }^{1} \mathrm{H}$ NMR of polyether 


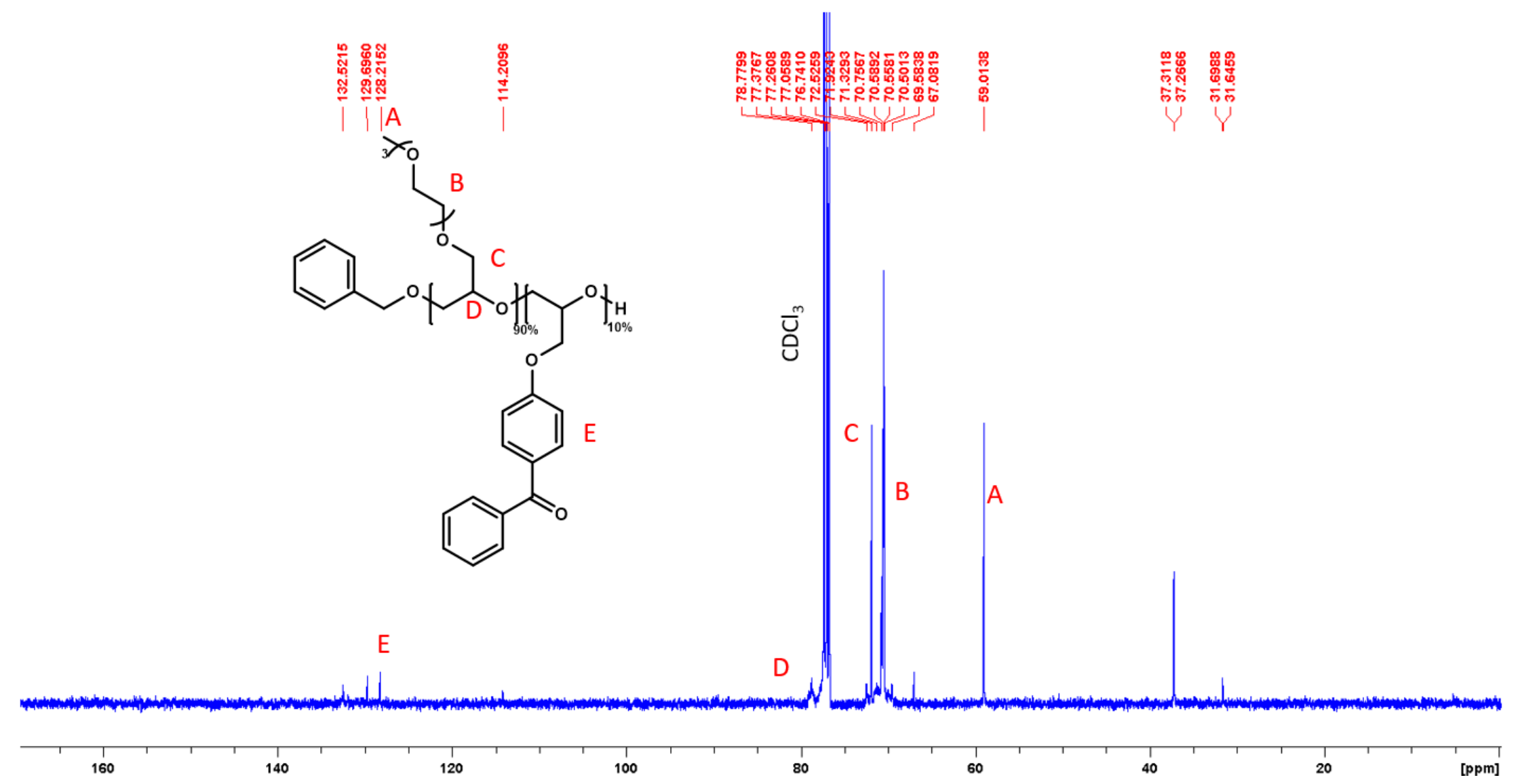

Figure S10. ${ }^{13} \mathrm{C}$ NMR of polyether 

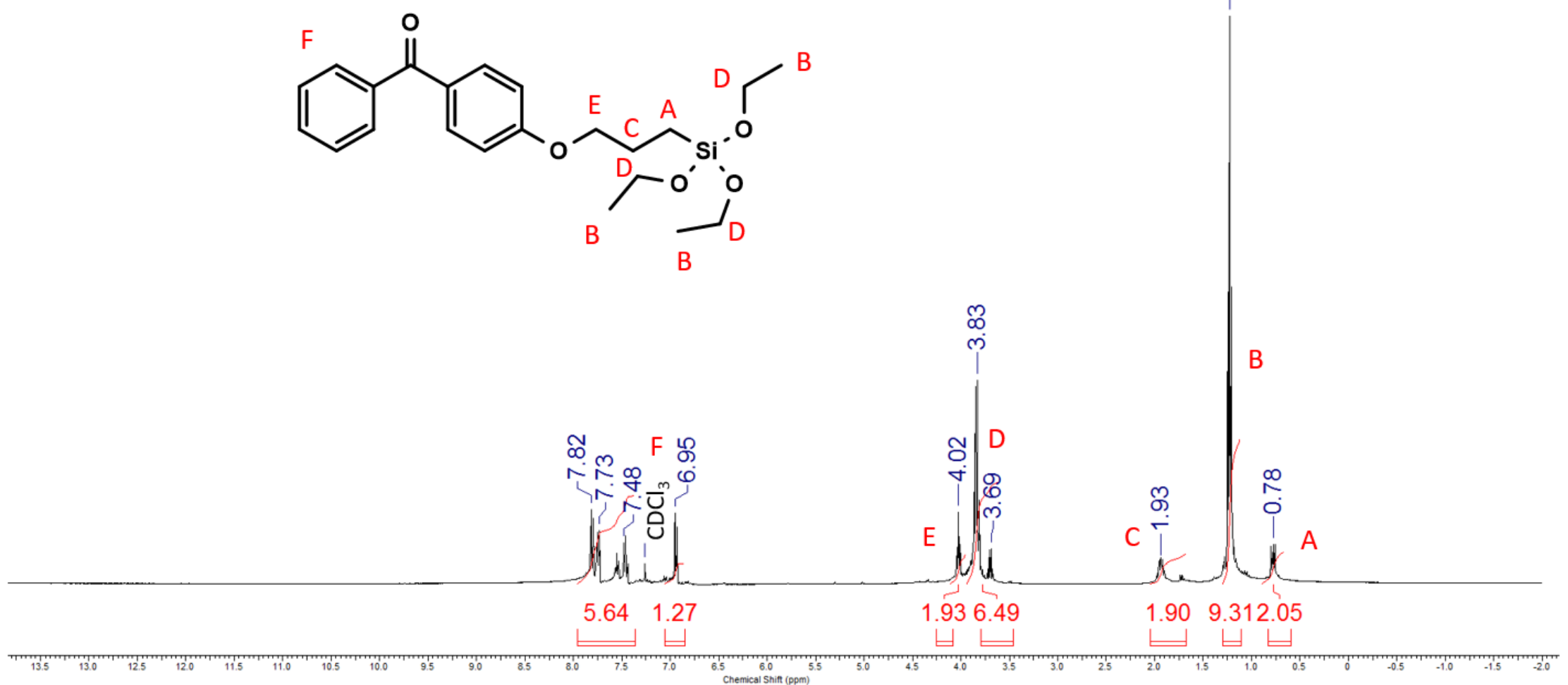

Figure S11. ${ }^{1} \mathrm{H}$ NMR of TESPBP 


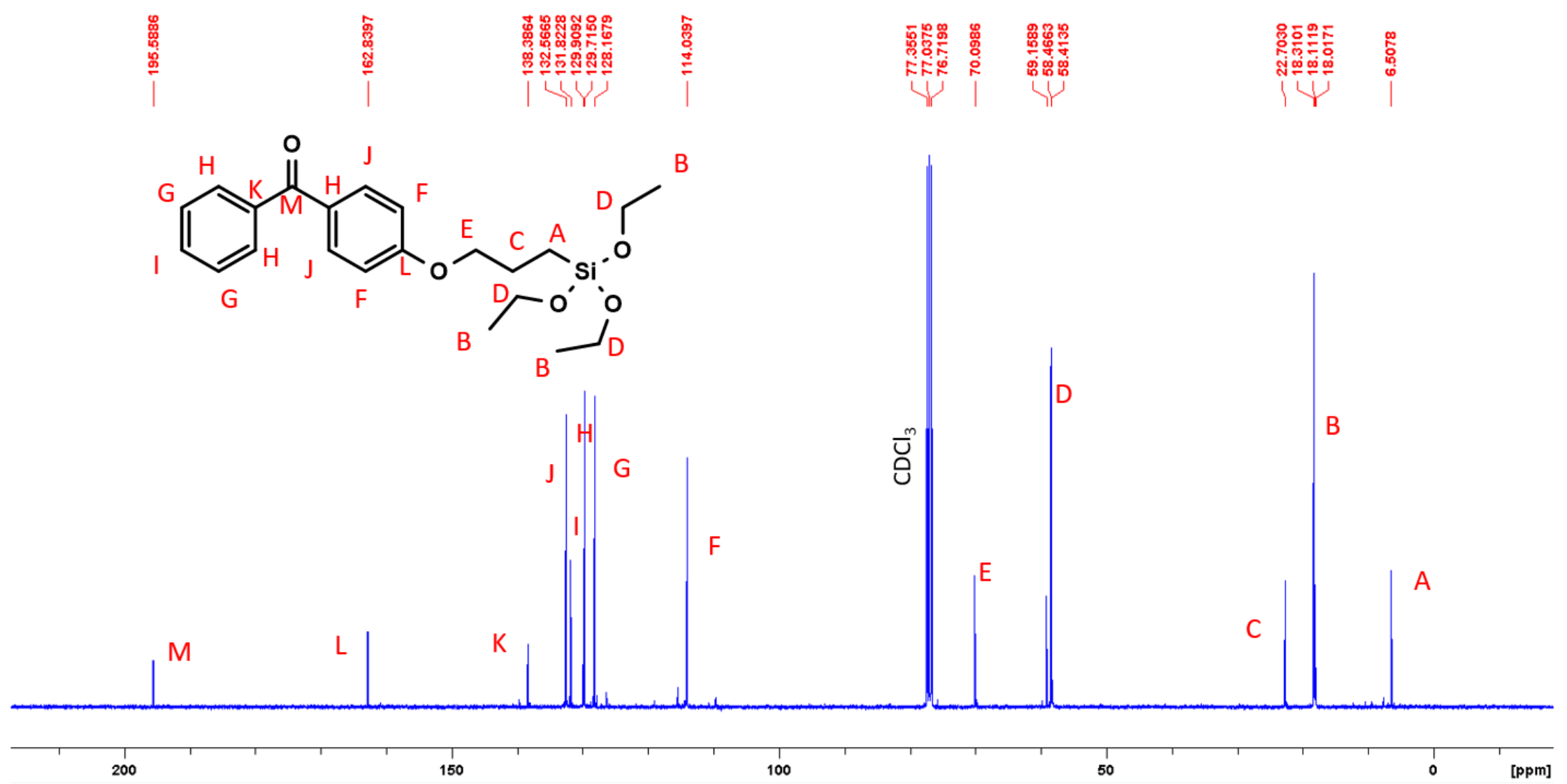

Figure S12. ${ }^{1} \mathrm{H}$ NMR of TESPBP 


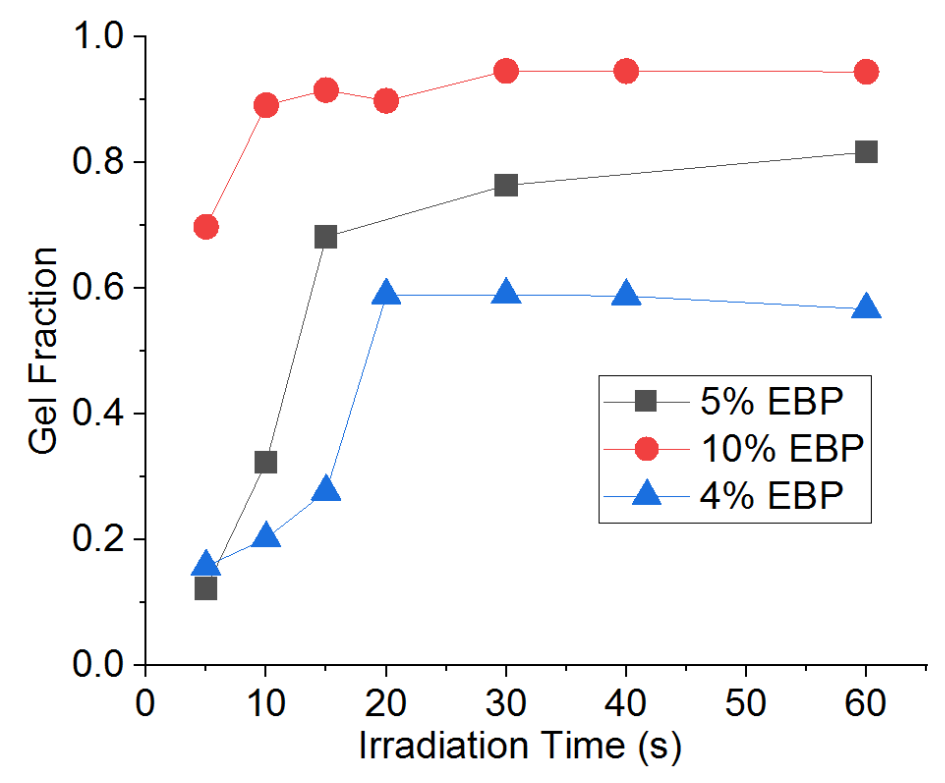

Figure S13. Gel Fraction versus irradiation time of samples with different percentage of EBP incorporation

(a)

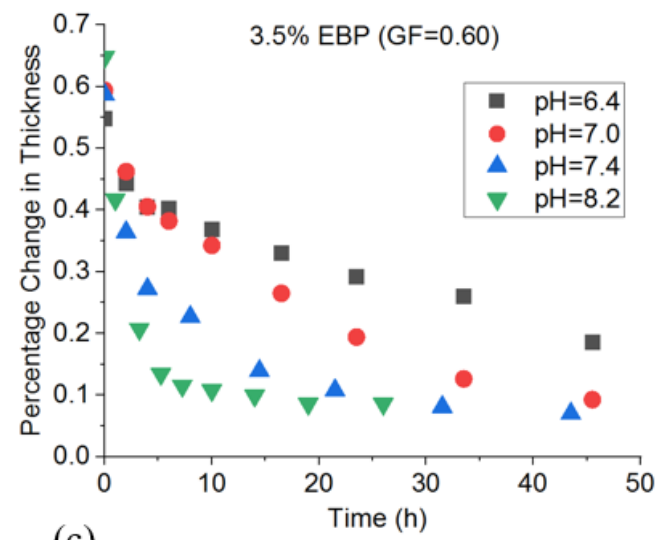

(c)

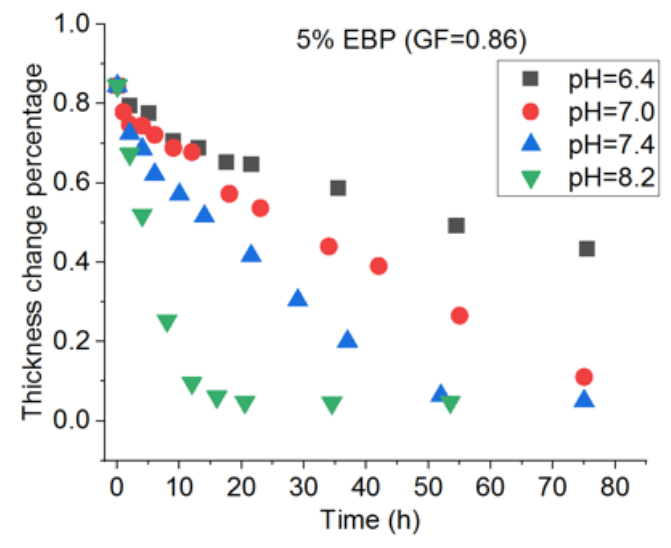

(b)
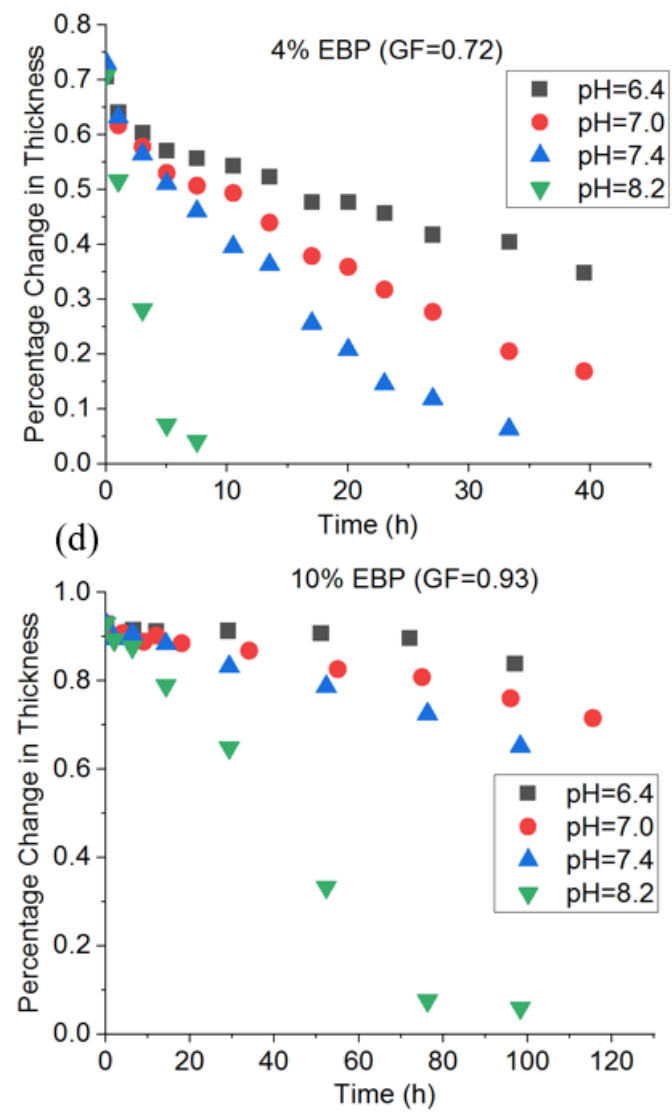

Figure S14. Percentage change in thickness versus $\mathrm{pH}$ for samples with various gel fractions $(\mathrm{GF}=0.60,0.72,0.86,0.93)$

Mu et al., "Supporting Information for Dynamic Surfaces..." $\quad$ Page S18 of S32 


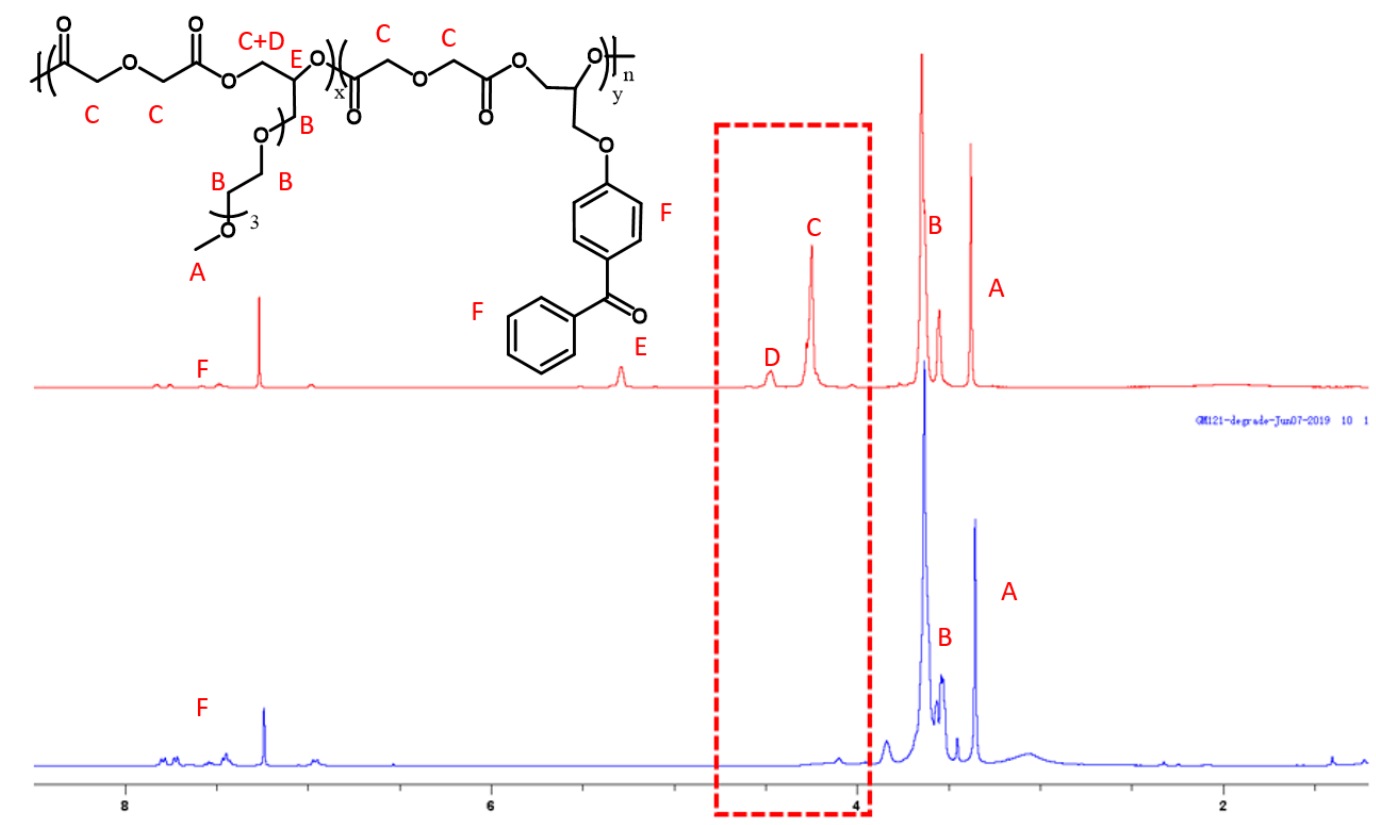

Figure S15. ${ }^{1} \mathrm{H}$ NMR of polyester before (red) and after (blue) degradation in basic solution

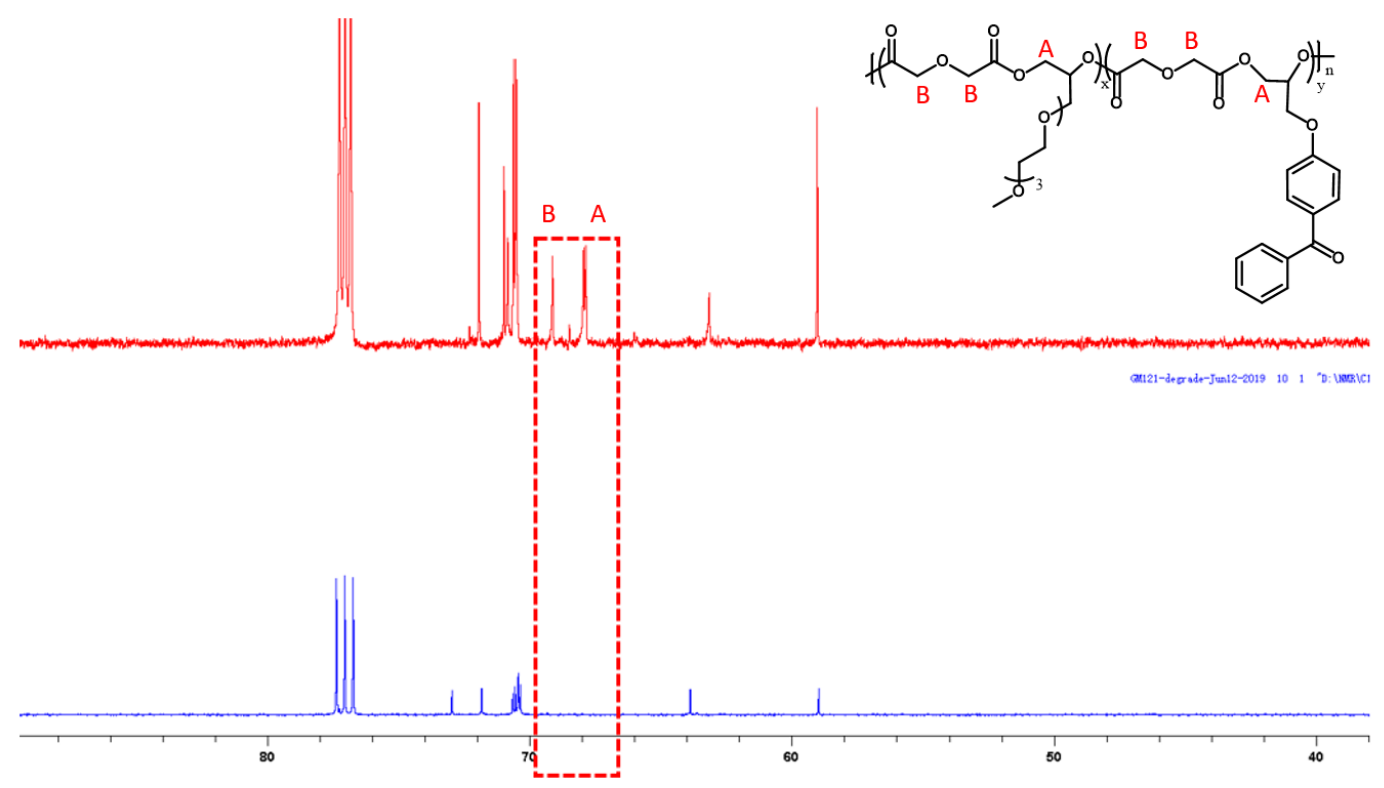

Figure S16. ${ }^{13} \mathrm{C}$ NMR of polyester before (red) and after (blue) degradation in basic solution 
(a)

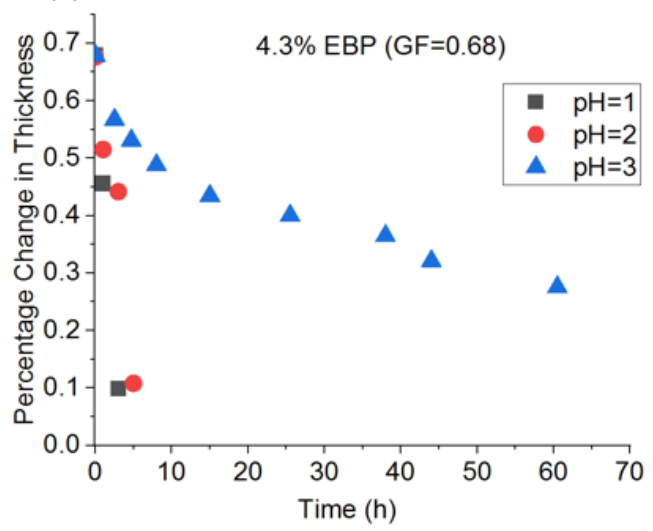

(c)

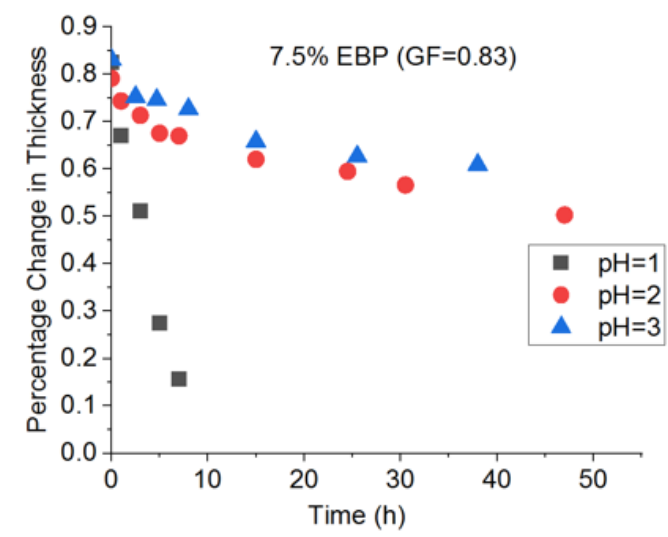

(b)

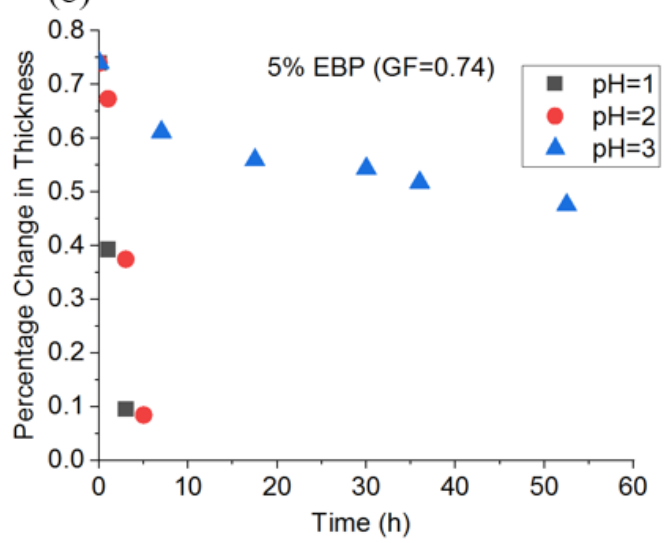

(d)

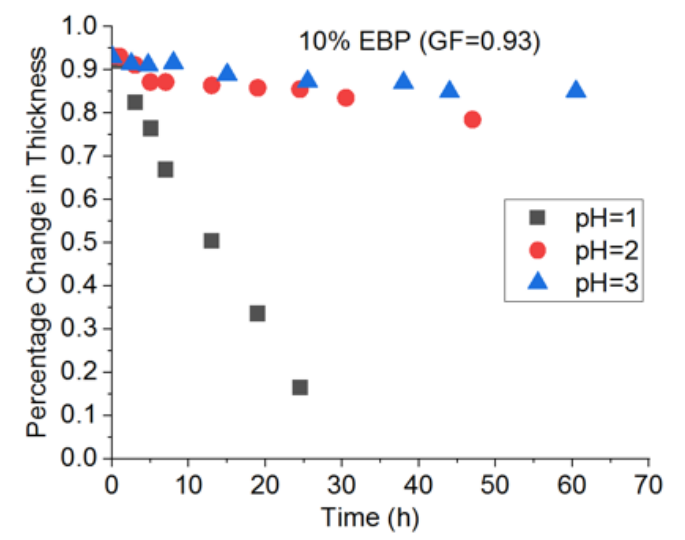

Figure S17. Degradation of polymers under acidic conditions shown as a percentage change in thickness versus immersion time. Values were obtained by ellipsometry

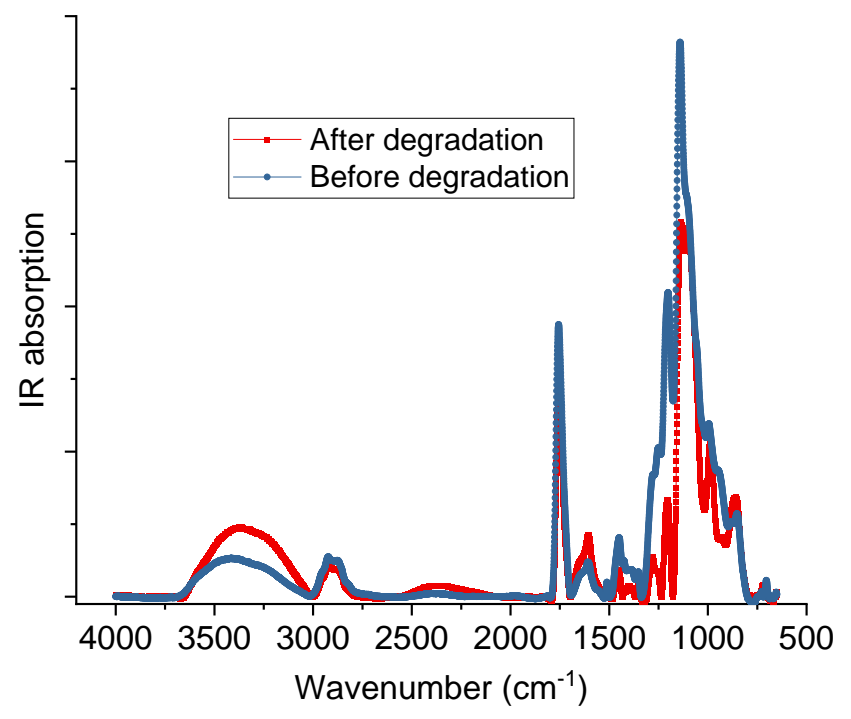

Figure S18. ATR-FTIR spectra of polyester network film spin-coated on a gold surface (blue) and incubated in $\mathrm{pH} 7.4$ buffer solution overnight (red). 


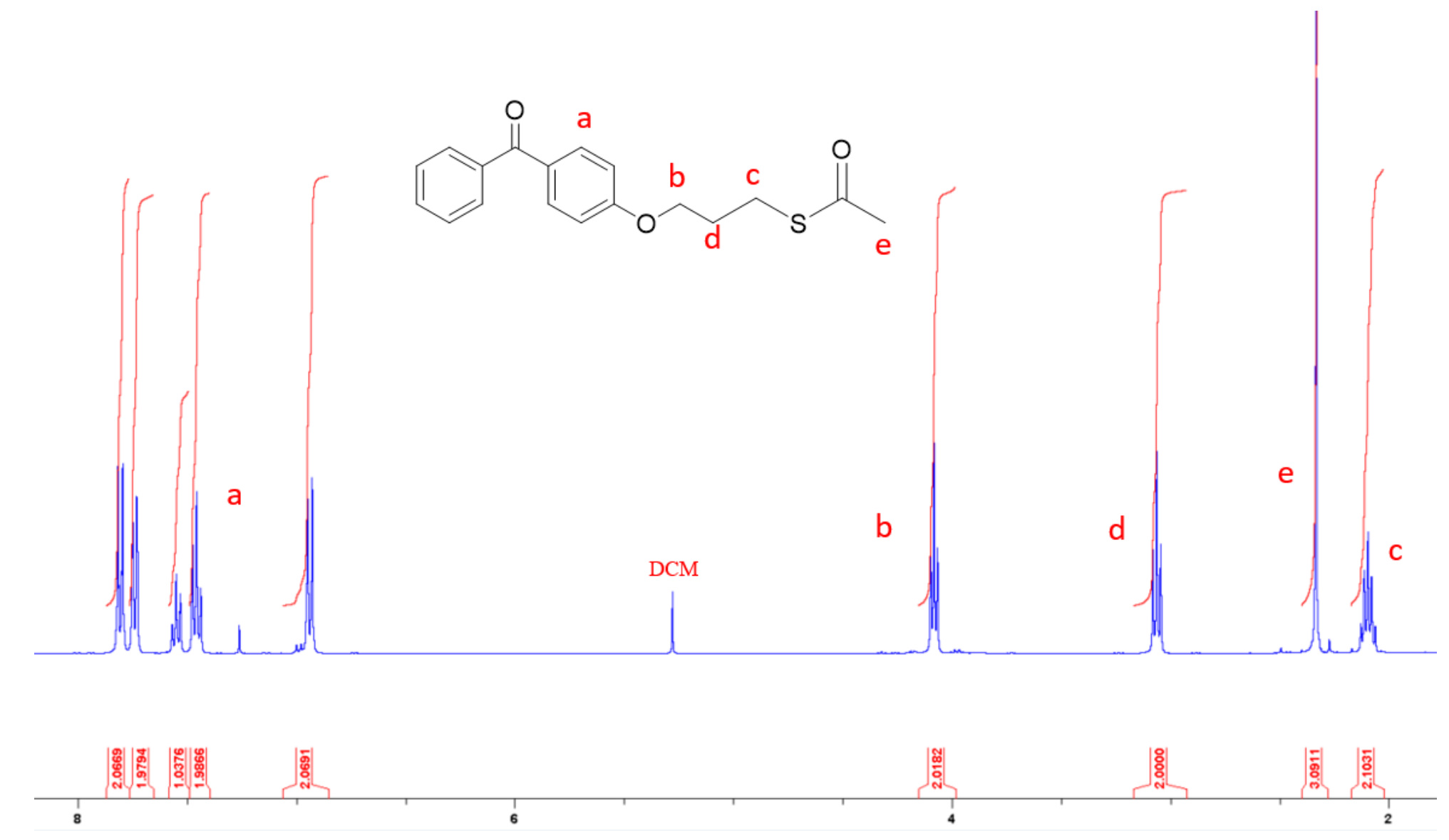

Figure S19. ${ }^{1}$ H NMR of S-(3-(4-benzoylphenoxy)propyl) ethanethiolate 


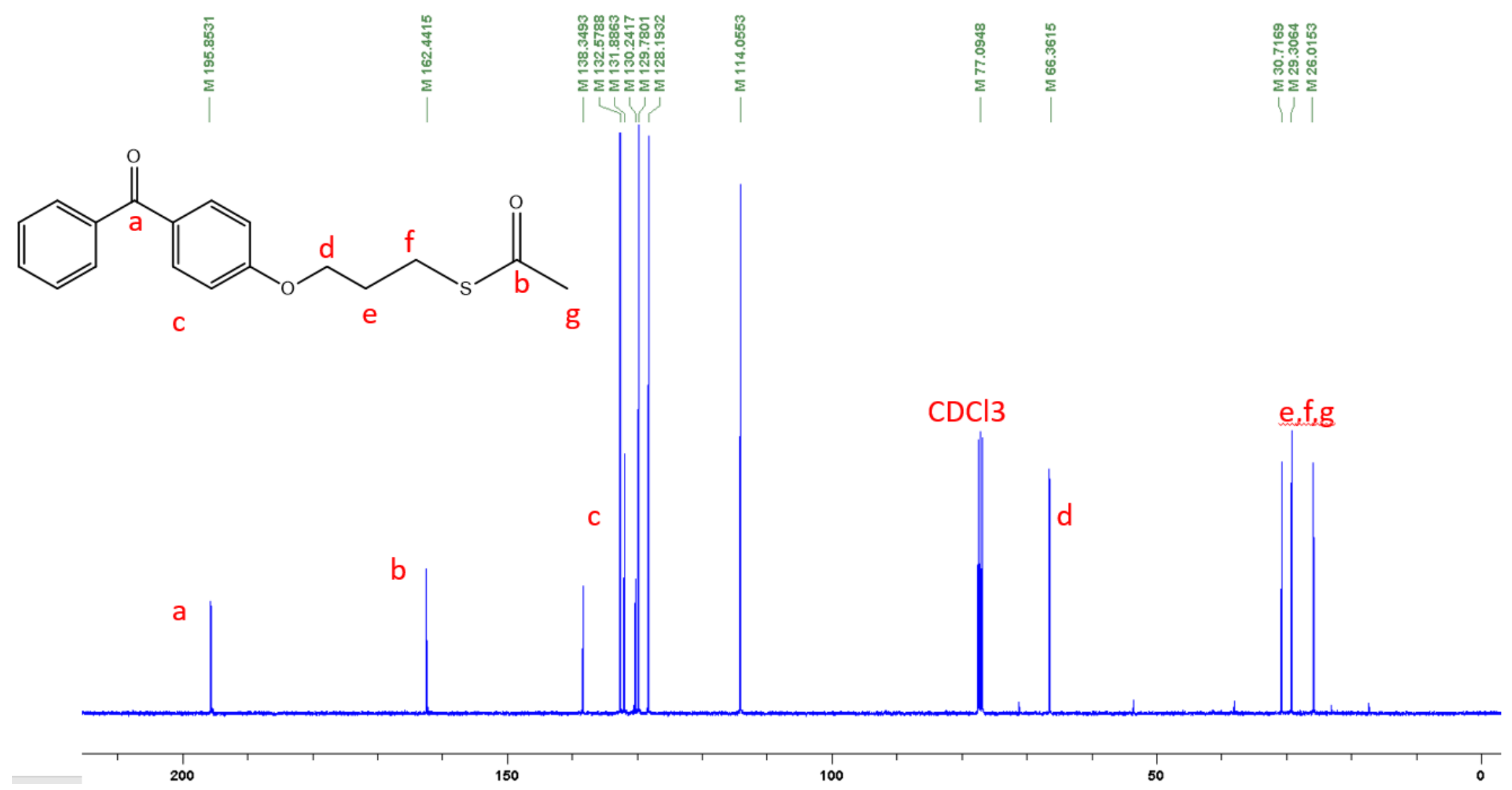

Figure S20. ${ }^{13} \mathrm{C}$ NMR of S-(3-(4-benzoylphenoxy)propyl) ethanethiolate 


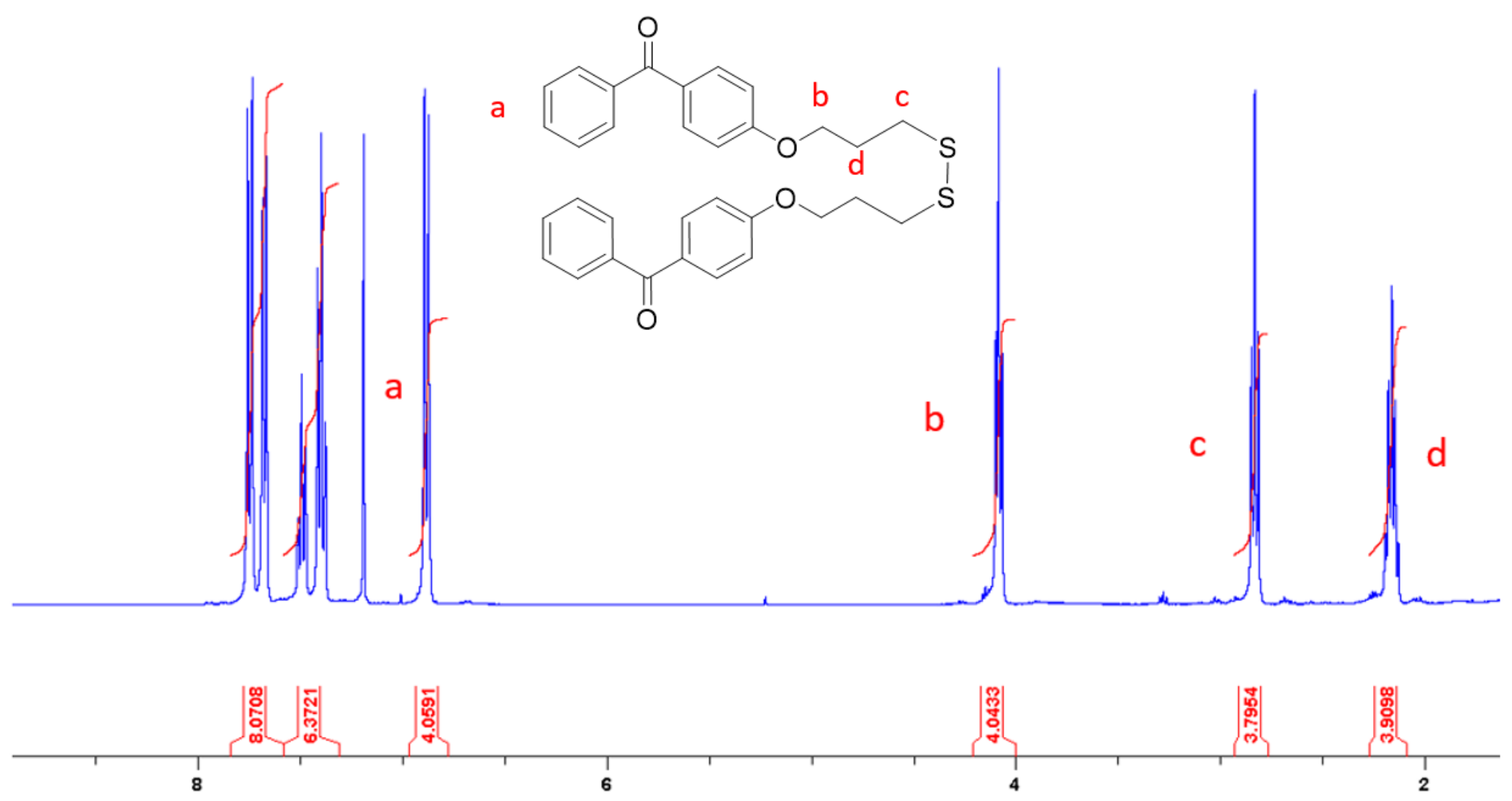

Figure S21. ${ }^{1} \mathrm{H}$ NMR of dibenzophenone disulfide 


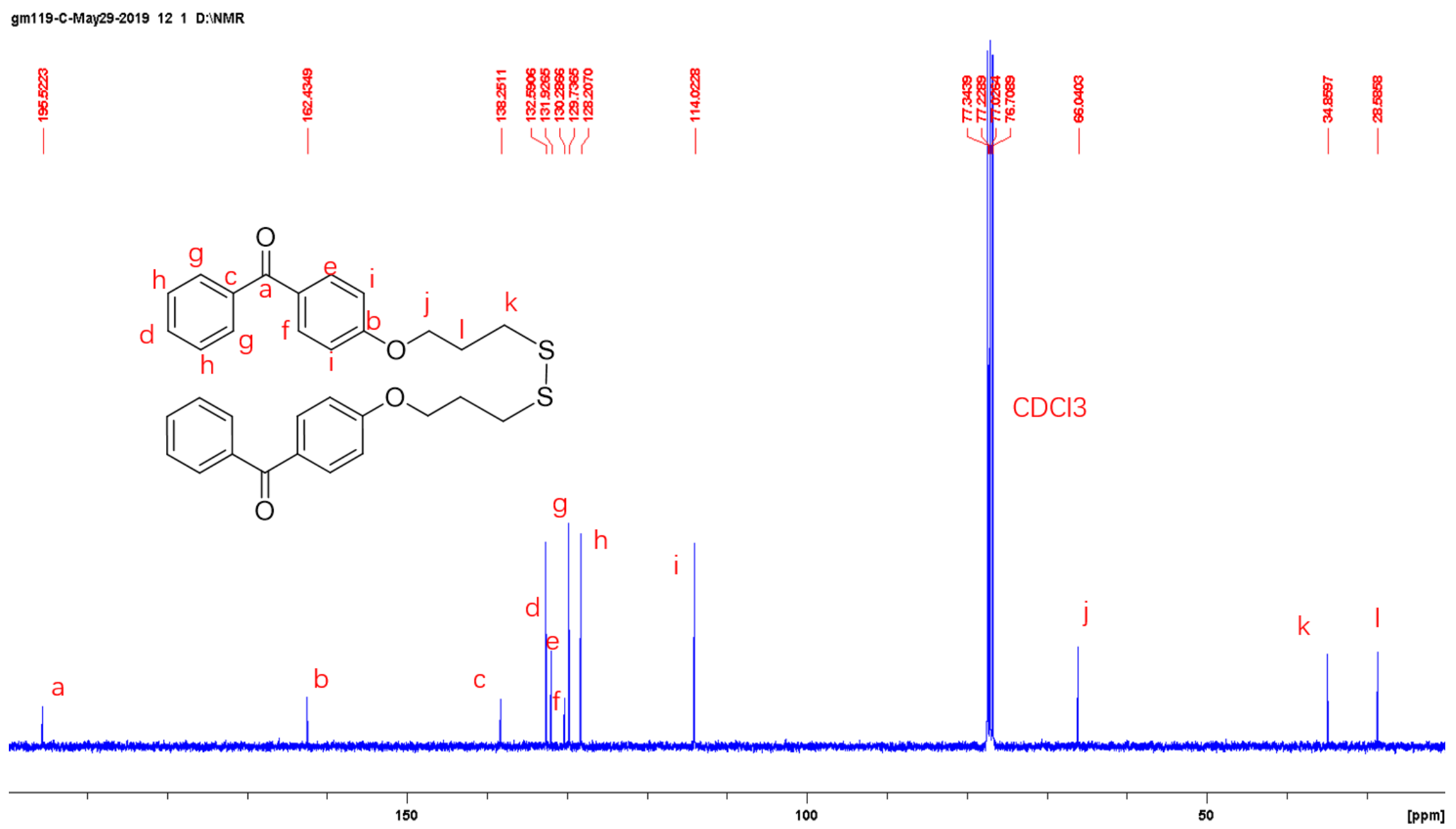

Figure S22. ${ }^{13} \mathrm{C}$ NMR of dibenzophenone disulfide 


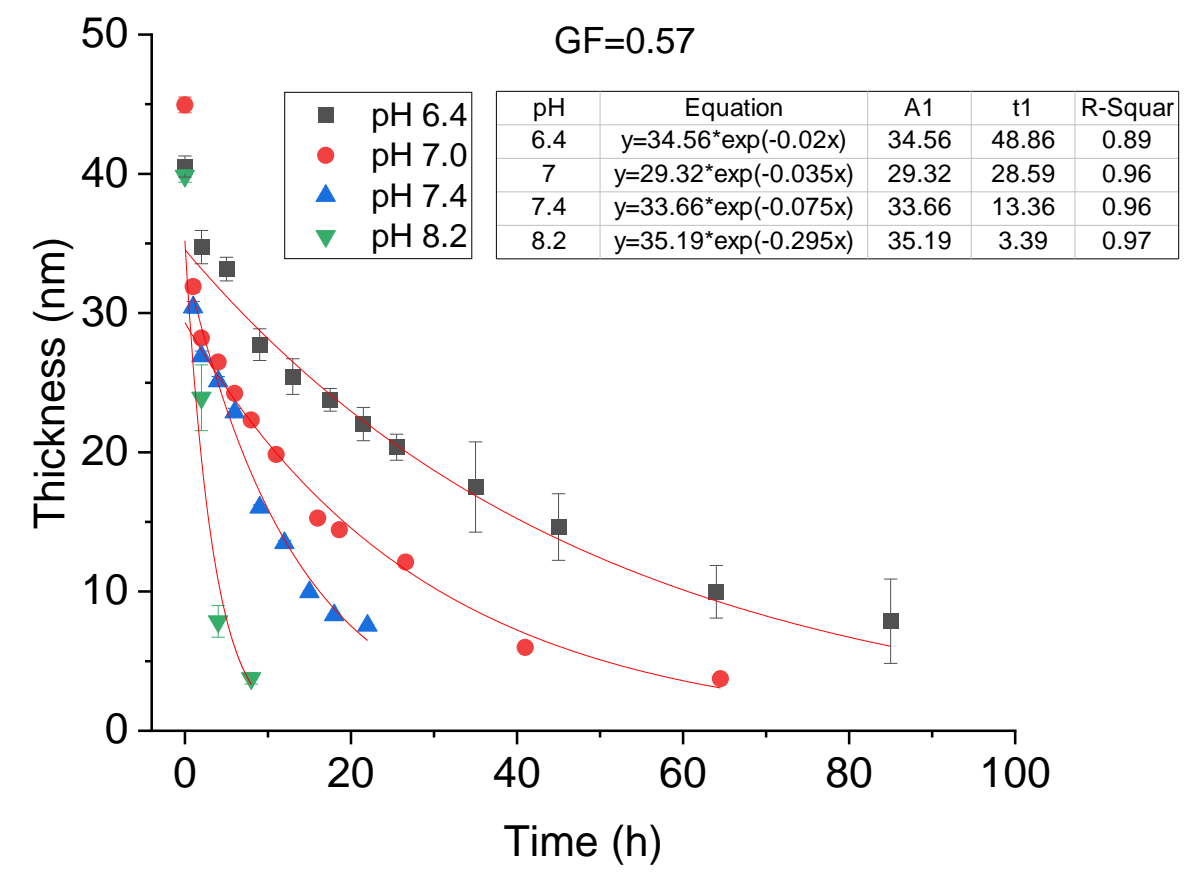

Figure S23. The degradation fitting curve of the network with the gel fraction of 0.57

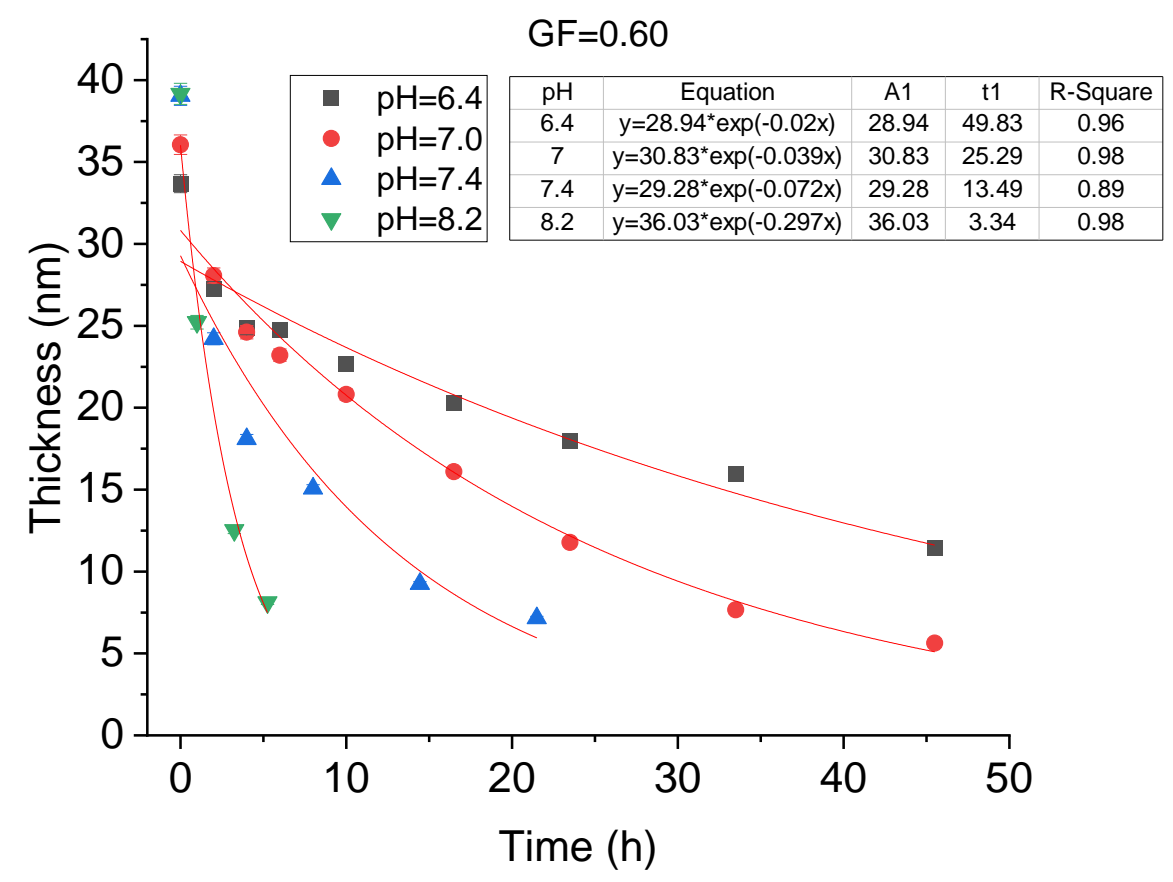

Figure S24. The degradation fitting curve of the network with the gel fraction of 0.60 


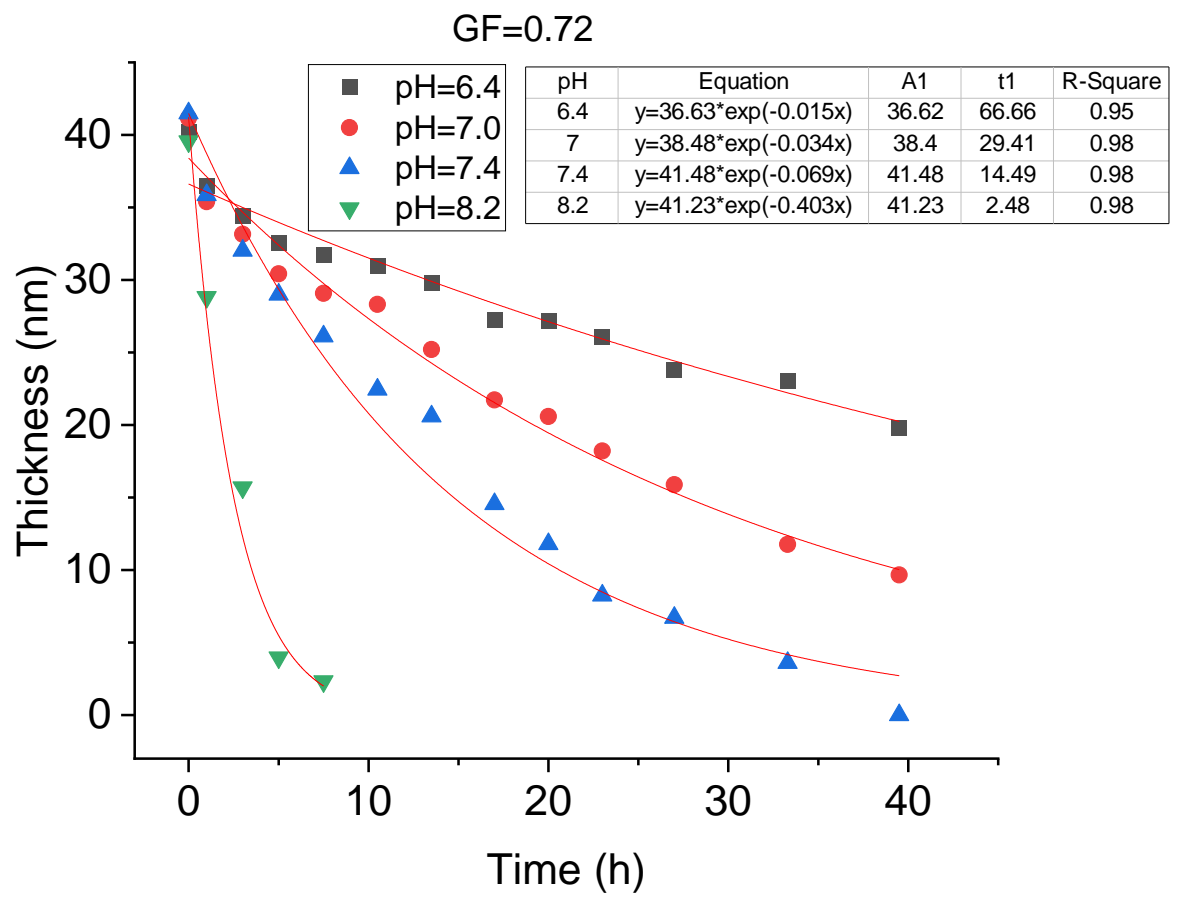

Figure S25. The degradation fitting curve of the network with the gel fraction of 0.72

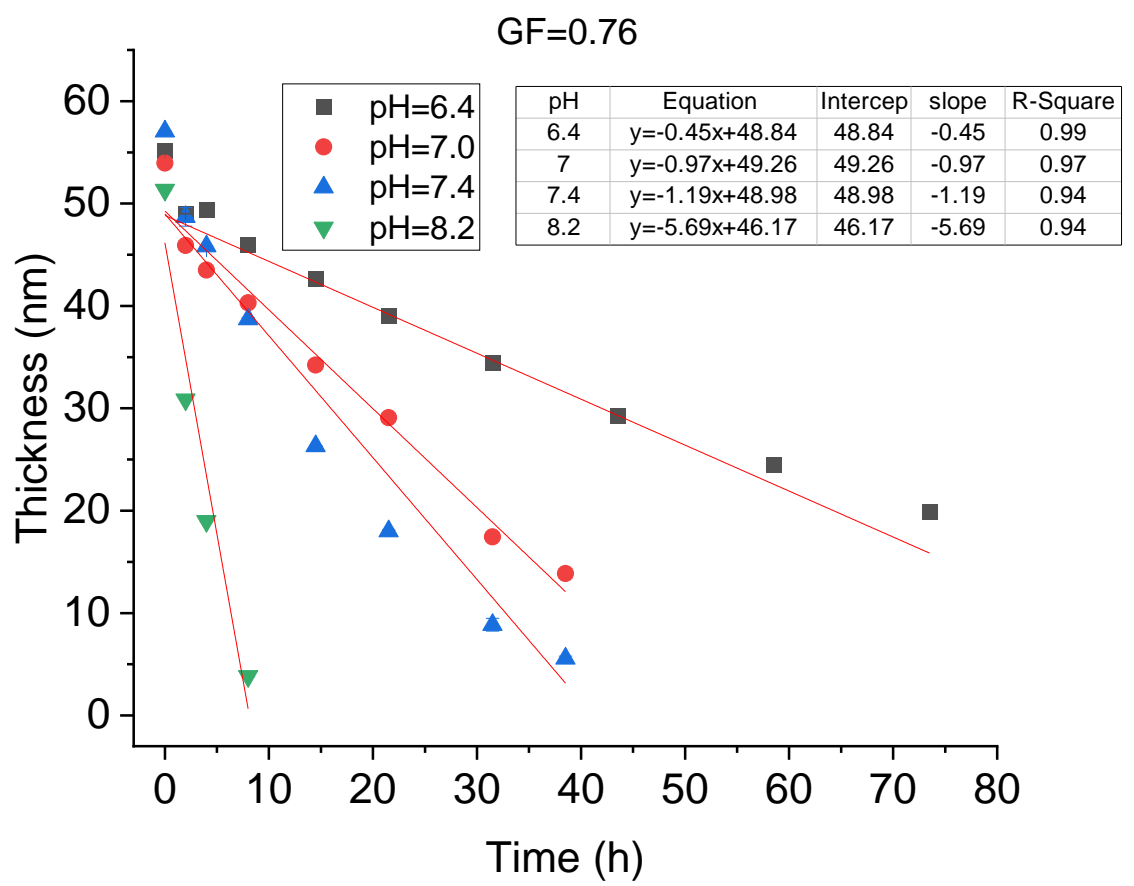

Figure S26. The degradation fitting curve of the network with the gel fraction of 0.76 


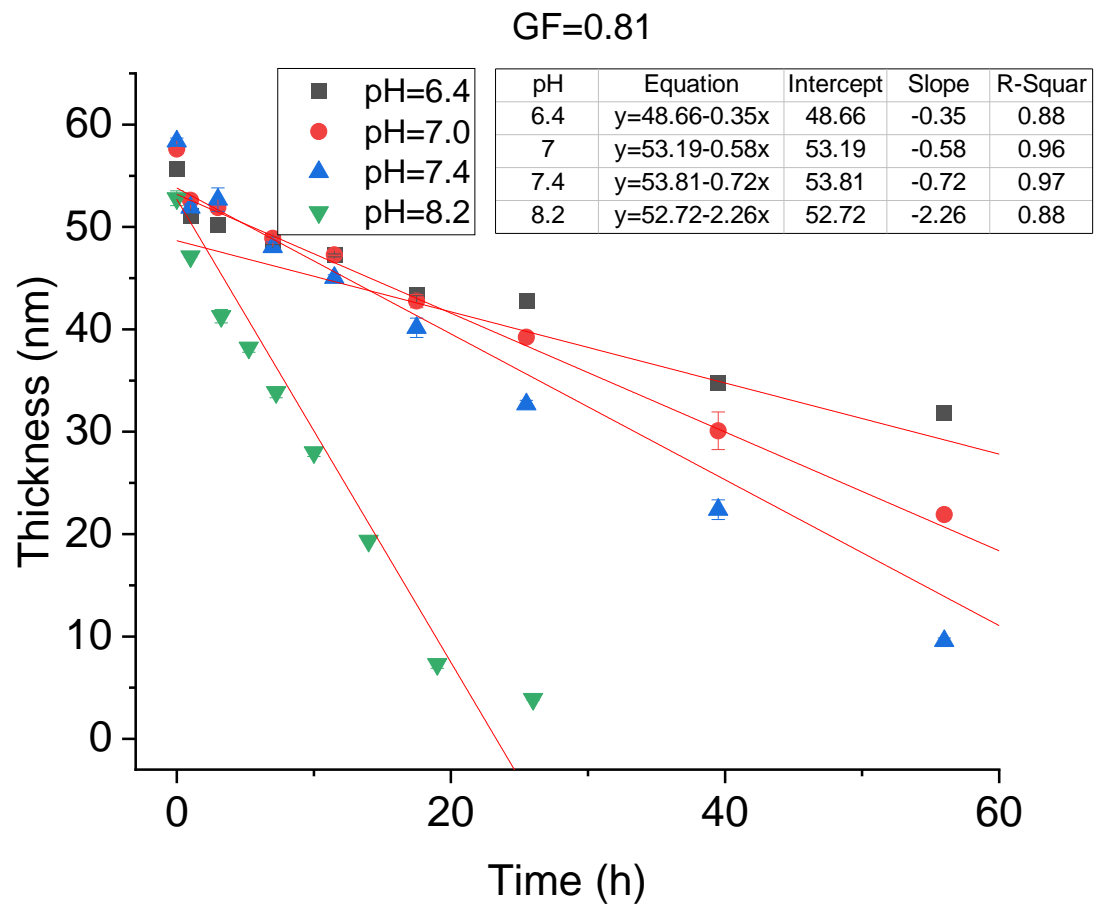

Figure S27. The degradation fitting curve of the network with the gel fraction of 0.81

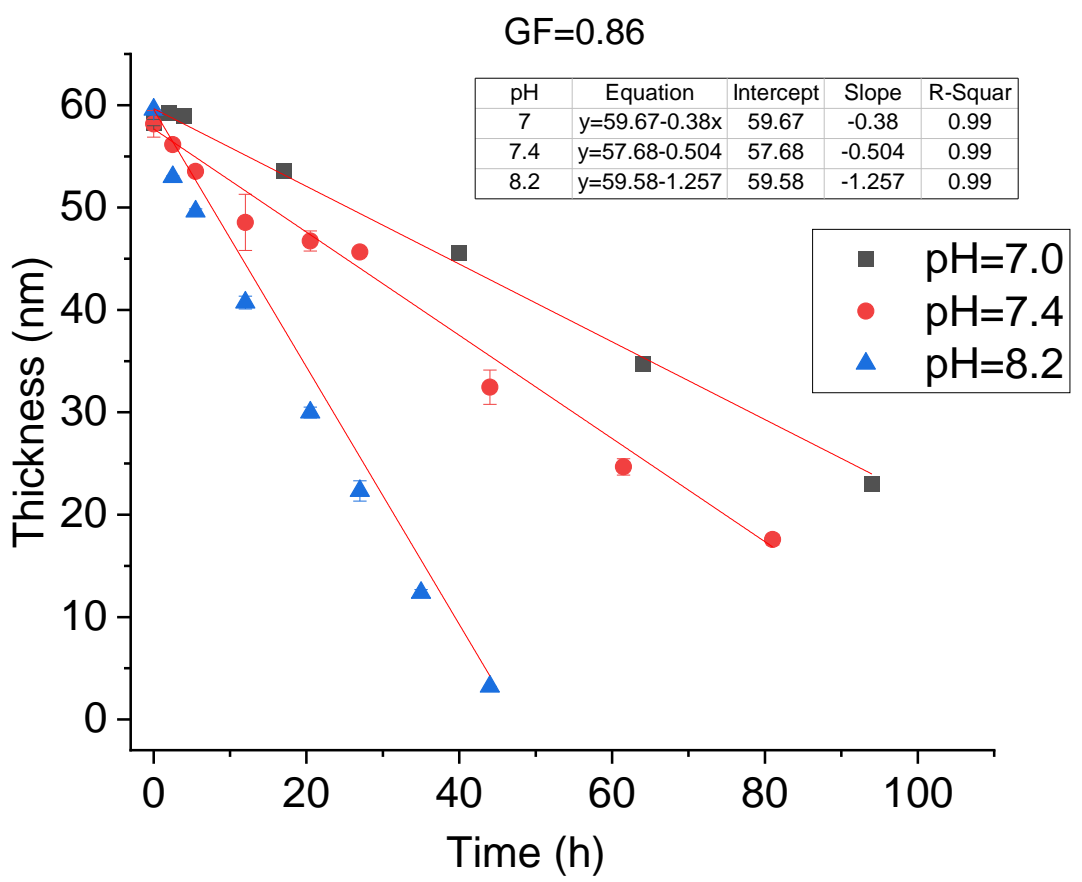

Figure S28. The degradation fitting curve of the network with the gel fraction of 0.86 


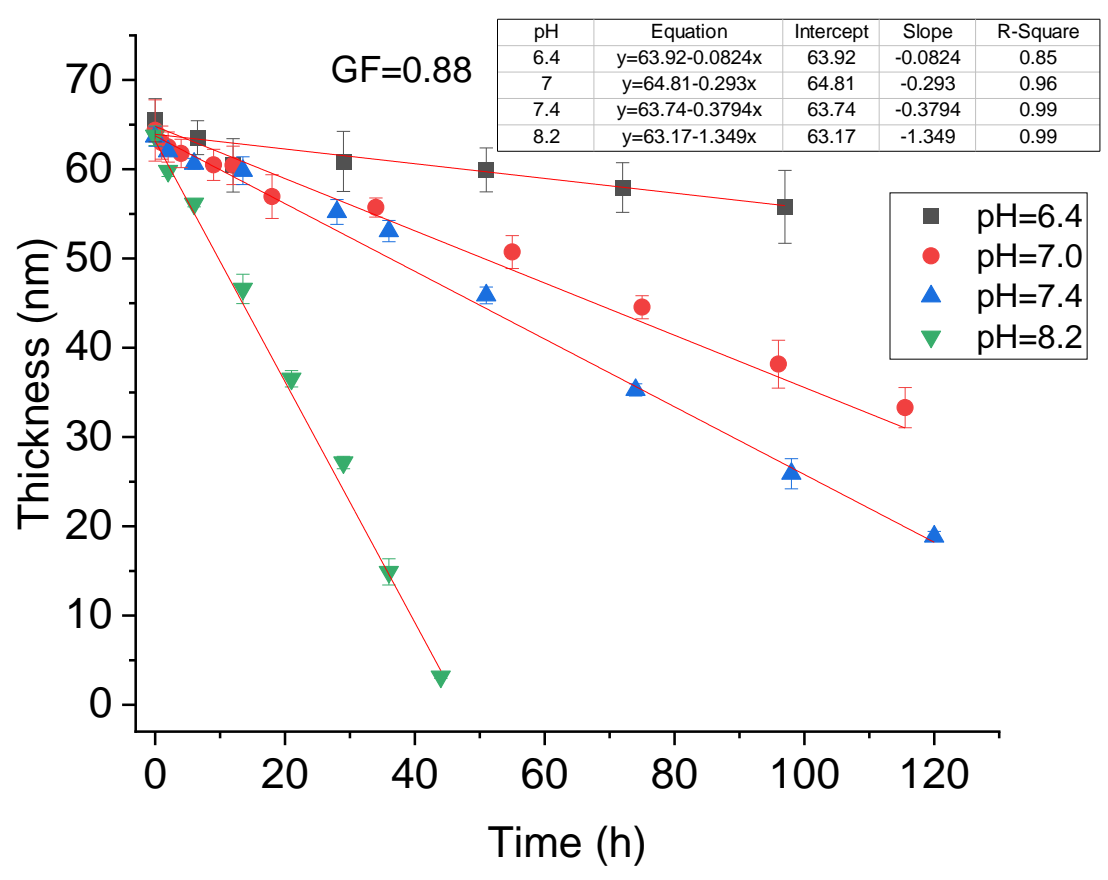

Figure S29. The degradation fitting curve of the network with the gel fraction of 0.88

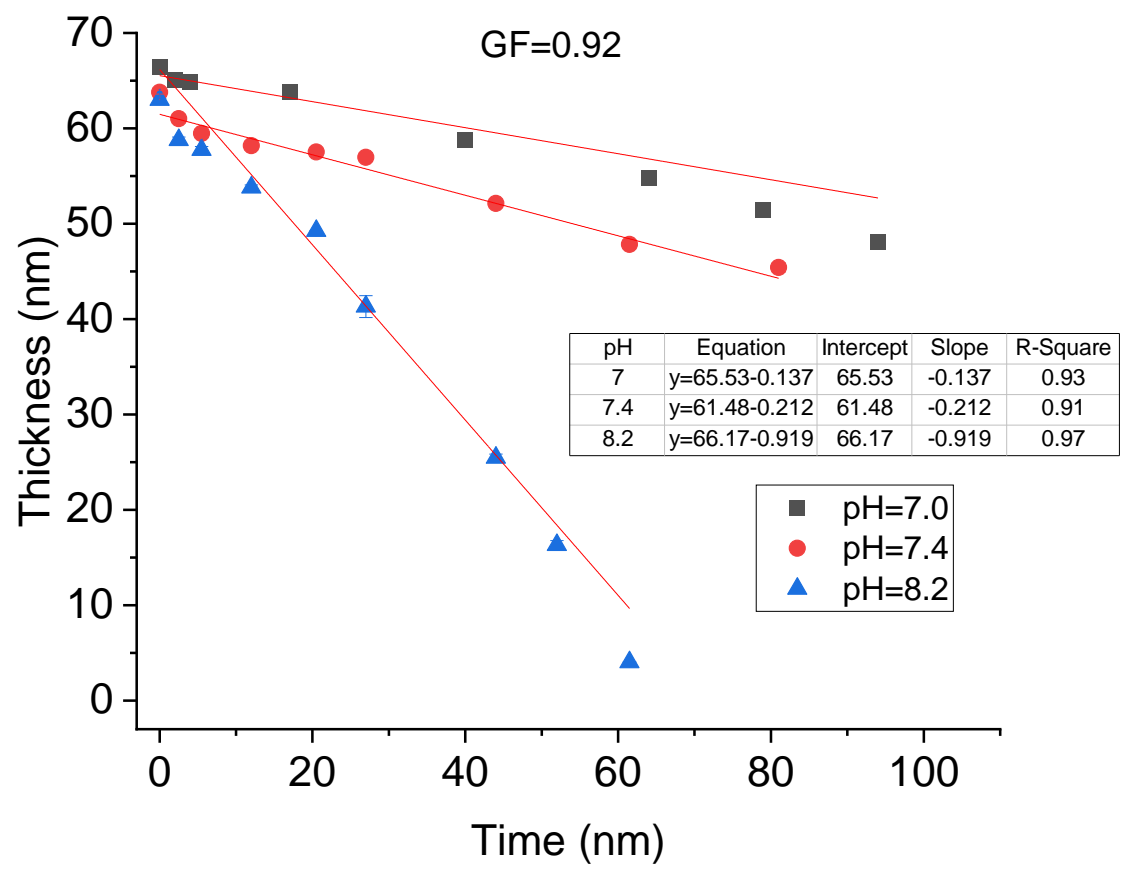

Figure S30. The degradation fitting curve of the network with the gel fraction of 0.92 


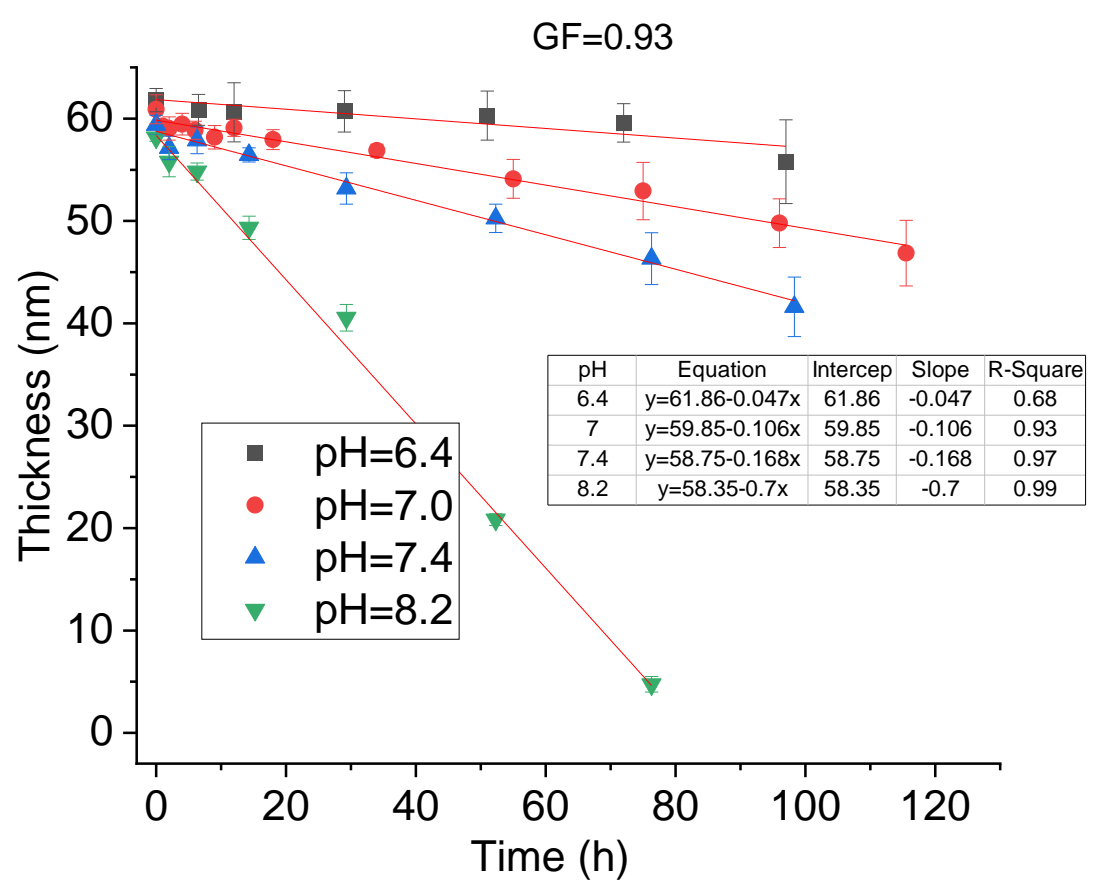

Figure S31. The degradation fitting curve of the network with the gel fraction of 0.93

(a)

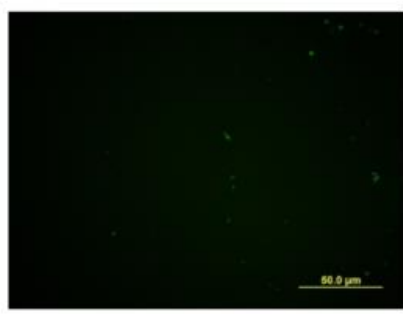

(d)

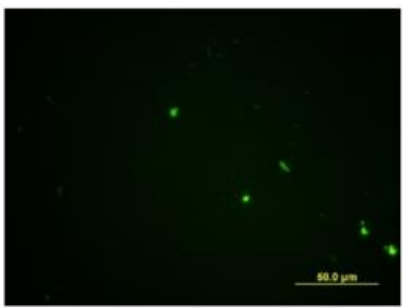

(b)

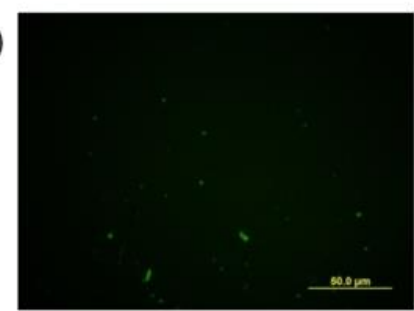

(e)

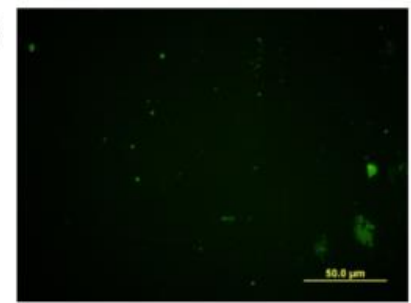

(c)

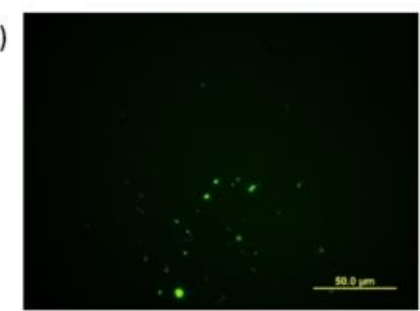

(f)

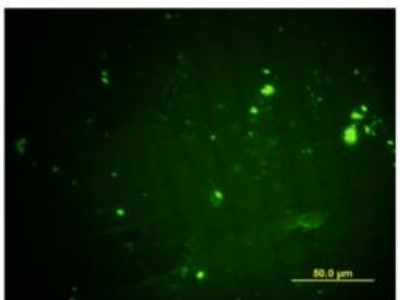

Figure S32. Fluorescence microscopy images showing BSA adsorption on thin films with various EBP ratio (a-f: $2.5 \%, 3.5 \%, 4.3 \%, 5 \%, 7.5 \%, 10 \%$ ) after $47.5 \mathrm{~h}$ immersion in FITC-BSA stock solution. The scale bars are $50 \mu \mathrm{m}$. 


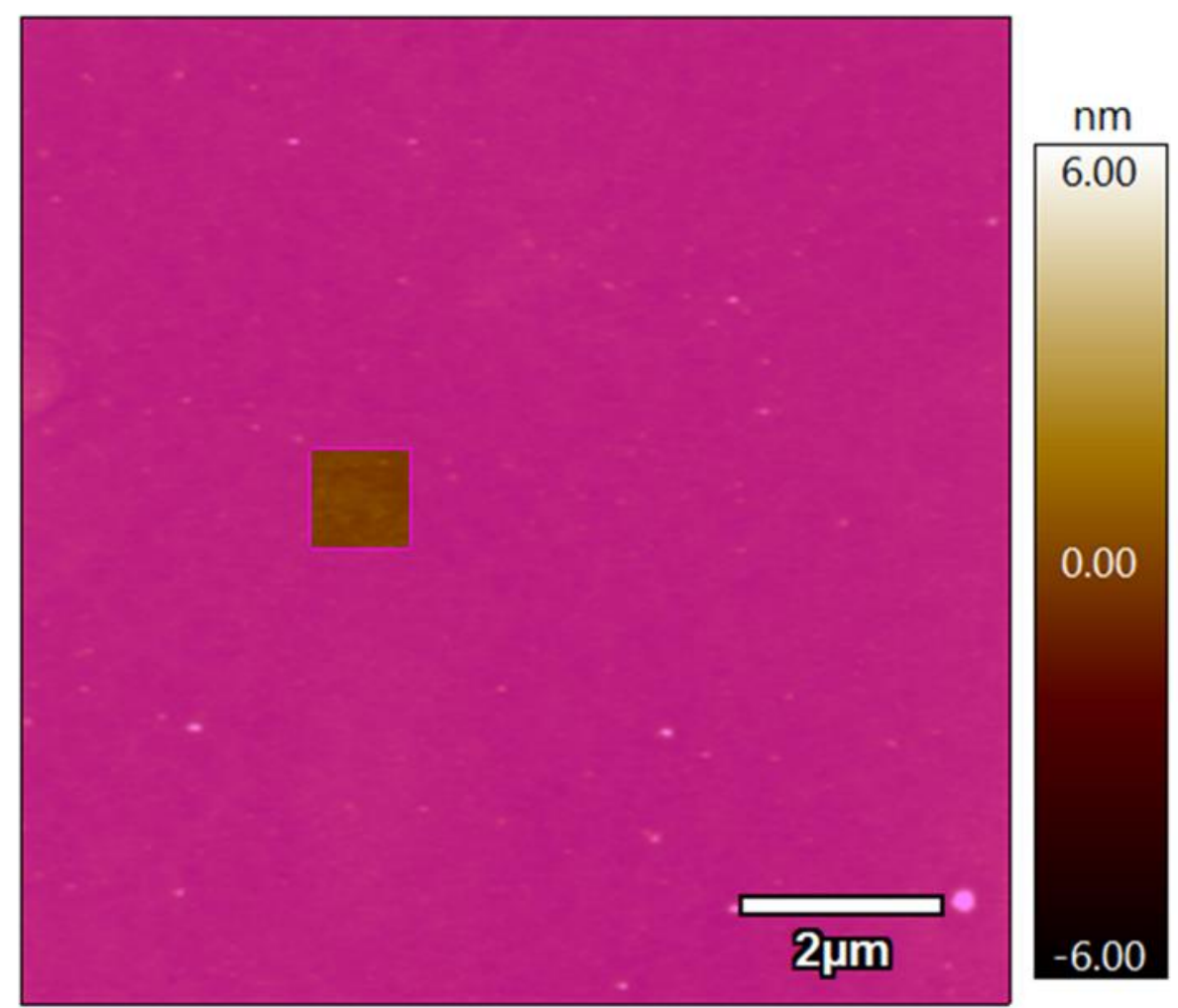

W72_0001HeightRetraceMod0

RoughnessData:

Parameter Full Image Values: Mask Image Values:

File: W72_0001

DataType: HeightRetraceMod0

Number Of Points:

$65536 \quad 676$

Date: $2019-05-28$

Image Note:

Average: $\quad 0.000 \mathrm{~m} \quad-85.842 \mathrm{pm}$

Standard Deviation: $\quad 382.873 \mathrm{pm} \quad 159.093 \mathrm{pm}$

Max: $\quad 35.207 \mathrm{~nm} \quad 681.276 \mathrm{pm}$

Min: $\quad-770.828 \mathrm{pm} \quad-507.823 \mathrm{pm}$

RMS: $\quad 382.870 \mathrm{pm} \quad 180.671 \mathrm{pm}$

Average Deviation: $\quad 162.445 \mathrm{pm} \quad 123.718 \mathrm{pm}$

ImagingMode: AC Mode

ScanLines: 256

ScanRate: $0.75 \mathrm{~Hz}$

Scansize: $10.00 \mathrm{~Hz}$

Skew. $\quad 40 \quad 0.405$

Kurtosis: $\quad 2.78 \mathrm{e}+03 \quad 0.936$

$\begin{array}{lll}\text { Percent XY: } & 100 \% & 1.031 \% \\ \text { Surface Area: } & 100.0 \mu \mathrm{m}^{2} & 990016.6 \mathrm{~nm}\end{array}$

$\begin{array}{llr}\text { Surface Area: } & 100.0 \mu \mathrm{m}^{2} & 990016.6 \mathrm{~nm}^{2} \\ \text { Area Percent: } & 0.004178 \% & 0.001292 \%\end{array}$

Volume $\quad 0.0 \mu \mathrm{m}^{3} \quad-0.0 \mu \mathrm{m}^{3}$

Figure S33. Roughness characterization of the polyester film by AFM 
File: PE_large_0001

DataType: HeightTraceMod0

Date: $2021-05-28$

ImageNote:

ImagingMode: AC Mode

ScanLines: 256

ScanPoints: 256

ScanRate: $1.00 \mathrm{~Hz}$

ScanSize: $1.00 \mu \mathrm{m}$

Time: 12:22:13 PM
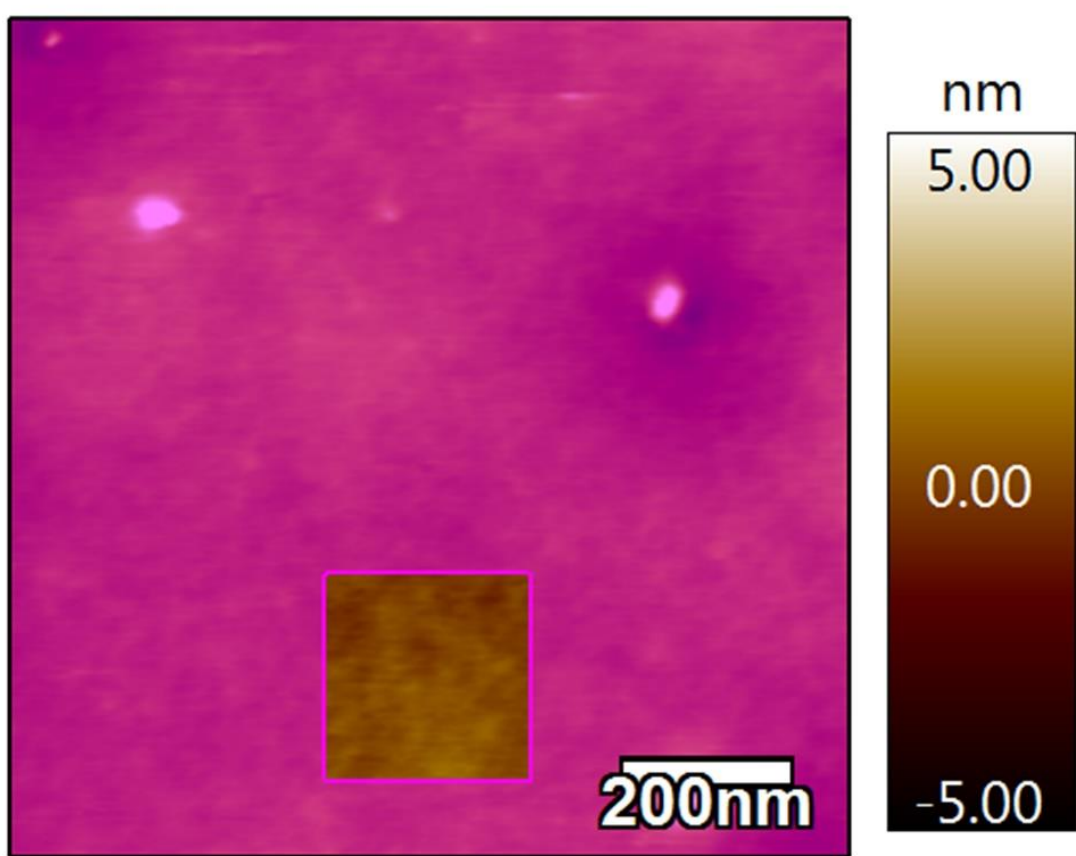

PE_large_0001HeightTraceModo

RoughnessData:

Parameter Full Image Values: Mask Image Values

Number Of Points:

Average:

$65536 \quad 4032$

$\begin{array}{ll}0.000 \mathrm{~m} & 111.845 \mathrm{pm} \\ 1.120 \mathrm{~nm} & 330.157 \mathrm{pm}\end{array}$

Min: $\quad-5.256 \mathrm{~nm} \quad-963.517 \mathrm{pm}$

Average Deviation: $\begin{array}{lll}1.120 \mathrm{~nm} & 348.548 \mathrm{pm} \\ 561.495 \mathrm{pm} & 264.913 \mathrm{pm}\end{array}$

Skew: $\quad 6.84 \quad 0.053$

Skew: $\quad 102-0.84$

$\begin{array}{lcc}\text { Kurtosis: } & 102 & -0.129 \\ \text { Percent XY: } & 100 \% & 6.152 \%\end{array}$

$\begin{array}{lll}\text { Percent XY: } & 100 \% & 6.152 \% \\ \text { Surface Area: } & 1.0 \mathrm{\mu m}^{2} & 60838.0 \mathrm{~nm}^{2}\end{array}$

Surface Area: $\quad 1.0 \mathrm{\mu m}^{2} \quad 60838.0 \mathrm{~nm}^{2}$

$\begin{array}{lcc}\text { Area Percent: } & 0.2446 \% & 0.08206 \% \\ \text { Volume } & 0.0 \mathrm{um}^{3} & 6935.1 \mathrm{~nm}^{3}\end{array}$

Figure S34. Roughness characterization of the polyether film by AFM 
File: PS_0002

DataType: HeightTraceModo

Date: 2021-05-28

ImageNote:

ImagingMode: AC Mode

ScanLines: 256

Scantines. 256

ScanRate: $1.00 \mathrm{~Hz}$

ScanSize: 100 um

Time: 12:42:09 PM

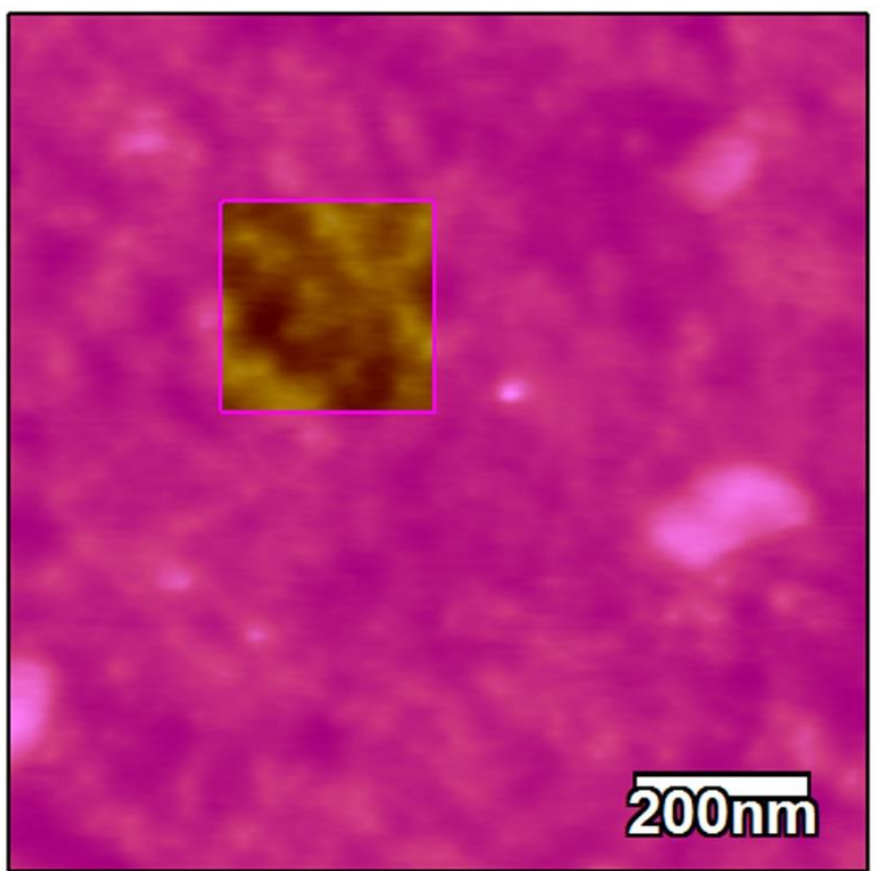

$\mathrm{nm}$

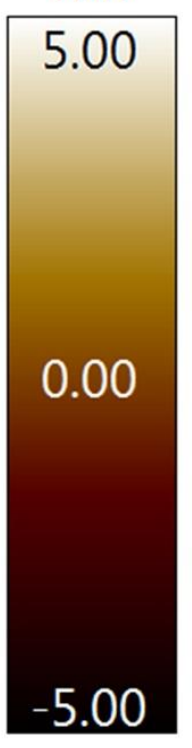

PS 0002HeightTraceMod0

RoüghnessData:

Parameter

Full Image Values: Mask Image Values:

Number Of Points:

$65536 \quad 4032$

Average: $\quad-0.000 \mathrm{~m} \quad-26.371 \mathrm{pm}$

Standard Deviation: $\quad 827.900 \mathrm{pm} \quad 724.104 \mathrm{pm}$

$\begin{array}{lll}\text { Max: } & 5.141 \mathrm{~nm} & 1.795 \mathrm{~nm} \\ & & -2.178 \mathrm{~nm}\end{array}$

RMS: $\quad 827.894 \mathrm{pm} \quad 724.494 \mathrm{pm}$

Average Deviation: $\quad 602.039 \mathrm{pm} \quad 590.555 \mathrm{pm}$

Skew: $\quad 1.3 \quad 0.0196$

Kurtosis: $\quad 4.03 \quad-0.585$

Percent XY: $\quad 100 \%-6.152 \%$

Surface Area: $\quad 1.0 \mu^{2} \quad 60875.4 \mathrm{~nm}^{2}$

Area Percent: $\quad 0.1317 \% \quad 0.1372 \%$

$\begin{array}{lll}\text { Volume } & -0.0{\mu \mathrm{m}^{3}}^{3} & -1635.2 \mathrm{~nm}^{3}\end{array}$

Figure S35. Roughness characterization of the polystyrene film by AFM 